\title{
About the Inverse Theory and the Non-Unicity of the Film Thickness: Novel Approach Generating Equivalent Micro-Grooves and Roughness
}

Mhammed ELGADARI ( $\nabla$ m.elgadari@ensam-umi.ac.ma )

Universite Moulay Ismail

HAJJAM Mohamed

Poitiers University: Universite de Poitiers

\section{Research Article}

Keywords: Reynolds equation, inverse theory, macro-shape, micro-texture, cavitation, lifting force, friction force, flow rate

Posted Date: February 23rd, 2021

DOI: https://doi.org/10.21203/rs.3.rs-229243/v1

License: (c) (i) This work is licensed under a Creative Commons Attribution 4.0 International License.

Read Full License 
February 09th, 2021

\section{Dear Editor,}

I wish to submit a new manuscript entitled "About the Inverse theory and the nonunicity of the film thickness: Novel approach generating equivalent micro-grooves and roughness" for consideration by the Tribology Letters.

I confirm that this work is original and has not been published elsewhere nor is it currently under consideration for publication elsewhere.

In this paper, throughout three surface finishes: the macro-shaped, micro-textured, and rough surfaces, it has been demonstrated that under a specific hydrodynamic pressure gradient, several film thicknesses could generate the same pressure field with a slight difference by considering cavitation. This is significant to confirm that different ratios of the averaged film thickness by the root mean square (RMS) similar hydrodynamic pressure could be generated, thereby the deficiency of this ratio to define the lubrication regime as commonly known with Patir and Cheng theory. The paper should be of interest to readers in the areas of lubricated contact based on the Inverse approach.

Please address all correspondence concerning this manuscript to me at “m.elgadari@ensam-umi.ac.ma..”

Thank you for your consideration of this manuscript.

Sincerely,

Prof. PhD. Mhammed El Gadari,

ENSAM Meknès Morrocco

Mechanics and Structural Analysis Department

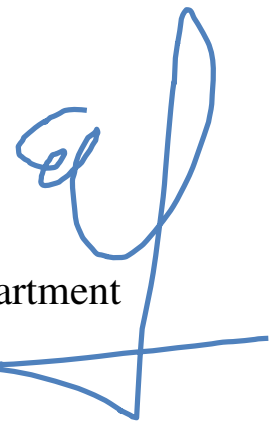




\section{Statement of Originality}

I confirm, Mhammed EL GADARI, that my submission to the Tribology Letters is my own original work.

Title paper: $\quad$ About the Inverse theory and the non-unicity of the film thickness: Novel approach generating equivalent micro-grooves and roughness

Author Nam: $\quad$ EL GADARI Mhammed

Co-Authors Nam: HAJJAM Mohamed

Date: February 09th, 2021

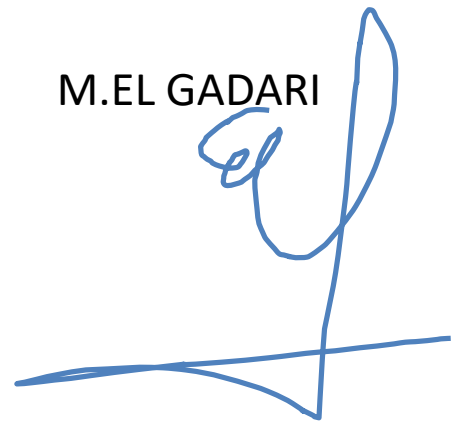




\section{About the Inverse theory and the non-unicity of the film thickness: Novel approach generating equivalent micro-grooves and roughness}

\section{Highlights :}

1) The non-unicity of the film thickness providing the same hydrodynamic pressure with cavitation effect was investigated.

2) For different lubricated contact, a novel approach generating several film thickness was computed: Macro-shaped surface, Micro-grooved surface without cavitation, Micro-grooved surface with cavitation effect, and rough surface.

3) The surface separation effect on the film thickness unicity was investigated.

4) This paper underlines that the dimensionless average film thickness " $\mathrm{h} 0 / \sigma$ " is not sufficient to determine the lubrication regime as commonly known with Patir and Cheng theory.

5) This novel approach gives engineers a numerical tool for changing geometry by maintaining the same lifting force and flow rate and minimizing the viscous friction effect

\section{Contact :}

Author : M'hammed El Gadari.

- Address : ENSAM-Meknes, Marjane II, B.P. 4024 Beni Mhamed, 50000, Meknes -Morocco;

- Mail: m.elgadari@ensam-umi.ac.ma;

- Cellular: +212613777708;

- Office Phone: $+212535467160 / 62$

- Fax: +212535467163/64

Co-Author (1): Mohamed Hajjam.

- Address : IUT- 4 Avenue de Varsovie, 16021, Angoulême CEDEX - France;

- Mail: Mohamed.hajjam@univ-poitiers.fr;

- Office Phone: +33545251979

- Fax: +33545670237 


\title{
About the Inverse theory and the non-unicity of the film thickness: Novel approach generating equivalent micro-grooves and roughness.
}

\author{
M. El Gadari a ${ }^{\text {, M. Hajjam }}{ }^{\text {b }}$ \\ ${ }^{a}$ University Moulay Ismail, ENSAM, Meknes, Morocco \\ ${ }^{b}$ Department D3, Pprime Institute, UPR3346, University of Poitiers, France
}

\begin{abstract}
:
Since the 1960s, all studies have assumed that a film thickness " $h$ " provides a unique pressure field "p" by resolving the Reynolds equation. However, it is relevant to investigate the film thickness unicity under a given hydrodynamic pressure within the inverse theory.
\end{abstract}

This paper presents a new approach to deduce from an initial film thickness a widespread number of thicknesses providing the same hydrodynamic pressure under a specific condition of gradient pressure. For this purpose, three steps were presented: 1) computing the hydrodynamic pressure from an initial film thickness by resolving the Reynolds equation with Gümbel's cavitation model, 2) using a new algorithm to generate a second film thickness, 3) comparing and validating the hydrodynamic pressure produced by both thicknesses with the modified Reynolds equation.

Throughout three surface finishes: the macro-shaped, micro-textured, and rough surfaces, it has been demonstrated that under a specific hydrodynamic pressure gradient, several film thicknesses could generate the same pressure field with a slight difference by considering cavitation. Besides, this paper confirms also that different ratios of the averaged film thickness by the root mean square (RMS) similar hydrodynamic pressure could be generated, thereby the deficiency of this ratio to define the lubrication regime as commonly known with Patir and Cheng theory. 
Keywords: Reynolds equation, inverse theory, macro-shape, micro-texture, cavitation, lifting force, friction force, flow rate.

\section{Introduction}

The differential equation that governs the generation of pressure in lubricating films is known as the Reynolds equation. In steady-state condition, this equation is given for one dimensional, isoviscous, and incompressible hydrodynamic lubrication problem by:

$$
\frac{d}{d x}\left(\frac{h^{3}}{6 \mu U} \frac{d p}{d x}\right)=\frac{d h}{d x}
$$

Where: " $x$ " the axial direction, " $U$ " the velocity of the lower surface, and " $\mu$ " the lubricant viscosity.

To design the lubricated components (bearings, thrust, seals ...) the equation (1) is solved by using two theories:

- The first is performed to dimension the supporting and/or guiding devices [1, 2, 3], so-called the direct approach. For a given film thickness, "h(x)" the pressure distribution, " $p(x)$ " within the fluid film is obtained by solving Reynolds equation (1).

- The second is the inverse method that is widely used for elastomeric seals. Indeed, according to this theory, the static contact pressure "ps(x)" is assumed equal to the hydrodynamic pressure " $\mathrm{p}(\mathrm{x})$ " and the film thickness " $\mathrm{h}(\mathrm{x})$ " is computed by using the first and second derivatives of " $\mathrm{p}(\mathrm{x})$ " $[4,5,6]$ under non-cavitation conditions.

This second method is based on the Reynolds equation and two computational procedures are possible (2) and (3): 


$$
\left\{\begin{array}{l}
\frac{h^{3}}{6 \mu U} \frac{d p}{d x}=h-h^{*} \\
\frac{d h}{d x}\left\{\frac{h^{2}}{2 \mu U} \frac{d p}{d x}-1\right\}+\frac{h^{3}}{6 \mu U} \frac{d^{2} p}{d x^{2}}=0
\end{array}\right.
$$

Usually, equation (2) is the most used in the inverse hydrodynamic lubrication [6] to determine " $h(x)$ " where " $h$ " is the film thickness at the location of the maximum pressure. The second approach is rarely used and is given by equation (3) with first and second derivative pressures " $\mathrm{dp} / \mathrm{dx}$ " and " $\mathrm{d}^{2} \mathrm{p} / \mathrm{dx}$ " .

Additionally, when the surface roughness is excessive, two approaches are used to resolve the Reynolds equation:

- Stochastic method, so-called Patir and Cheng flow factors method [7] by solving the transformed (or averaged) Reynolds equation for micro bearings having a realistic surface roughness.

- Deterministic method by assuming the rough surface as an analytical function. In most cases, it is given by sinusoidal form [8].

The proposed method describes a new approach to find different geometries, microgrooves, and roughnesses of the lubricated contact that keep the same operational parameters: friction force $\mathrm{F}$ flow rate $\mathrm{Q}$ and lifting force $\mathrm{W}$.

$$
\left\{\begin{array}{l}
W=\int_{0}^{L} p d x \\
F=\int_{0}^{L}-\left(\frac{\mu U}{h}+\frac{h}{2} \frac{d p}{d x}\right) d x \\
Q=\frac{-h^{3}}{12 \mu} \frac{d p}{d x}+\frac{U h}{2}
\end{array}\right.
$$

To consider the cavitation effect, the most used methods are: 
Method 1: Since 1921, Gümbel [11] has proposed simply to neglect pressures less than atmospheric pressure. Thus, to compute the hydrodynamic pressure in a full film lubricated contact, Reynolds equation (1) is resolved with the cavitation condition:

$$
p=p_{\text {cav }} \text { where } p \leq p_{\text {atm }}
$$

- Method 2: The following modified Reynolds equation [12] is resolved:

$$
\frac{\mathrm{d}}{\mathrm{dx}}\left(\mathrm{h}^{3} \frac{\mathrm{d} \phi \mathrm{D}}{\mathrm{dx}}\right)=6 \mu \mathrm{U}\left(\frac{\mathrm{dh}}{\mathrm{dx}}+\frac{\mathrm{d}(1-\phi) \mathrm{D}}{\mathrm{dx}}\right)
$$

where $\phi$ the cavitation index equal to 0 in the cavitation zone when $\mathrm{D} \leq 0$ and equal to 1 in the active zone when $\mathrm{D}>0$.

By considering the replenishment $r$, where $\rho$ and $\rho_{0}$ are the density of cavitated zone and lubricant respectively:

$$
r=\frac{\rho}{\rho_{0}} h
$$

We admit also:

$$
\begin{cases}p=D & \text { and } r=h, \quad \text { when } \phi=1 \\ p=p_{\text {cav }} & \text { and } r=D+h, \quad \text { else }\end{cases}
$$

Before beginning the numerical analysis, the reader must keep in mind the processing steps:

-First analysis: With an initial film thickness " $\mathrm{H}_{1}(\mathrm{x})$ ", the Reynolds equation (1) is resolved, and the hydrodynamic pressure " $p(x)$ " with cavitation effect is searched according to Gümbel [11] condition.

-Second analysis: Based on the hydrodynamic pressure " $p(x)$ " of the first analysis an original approach is proposed to compute all the different film thicknesses " $\mathrm{H}_{2}(\mathrm{x})$ ". 
-Third analysis: By replacing the two film thicknesses " $\mathrm{H}_{1}(\mathrm{x})$ " and " $\mathrm{H}_{2}(\mathrm{x})$ " in the modified Reynolds equation (6), the hydrodynamic pressure for each film thickness is computed to compare and discuss the accuracy of the approach.

\section{Numerical approach}

\subsection{Computing the hydrodynamic pressure}

The proposed approach consists of two depending on steps:

- Step 1: By using an appropriate numerical method (finite differences, finite volumes, and finite elements, analytic ...), the Reynolds equation (1) corresponding to the first analysis and modified Reynolds equation (6) for the third analysis is resolved. Thus, according to the computed pressure $\mathrm{p}(\mathrm{x})$, the lifting force $\mathrm{W}$ the friction force $\mathrm{F}$, and the flow rate $\mathrm{Q}$ are deduced from equations (4).

In this initial step, the film thickness $\mathrm{h}(\mathrm{x})$ is assumed known and equal to the guessed initial thickness $\mathrm{H}_{1}(\mathrm{x})$.

Equations (1) and (6) are discretized with the classical finite volumes method briefly described in figure 1.

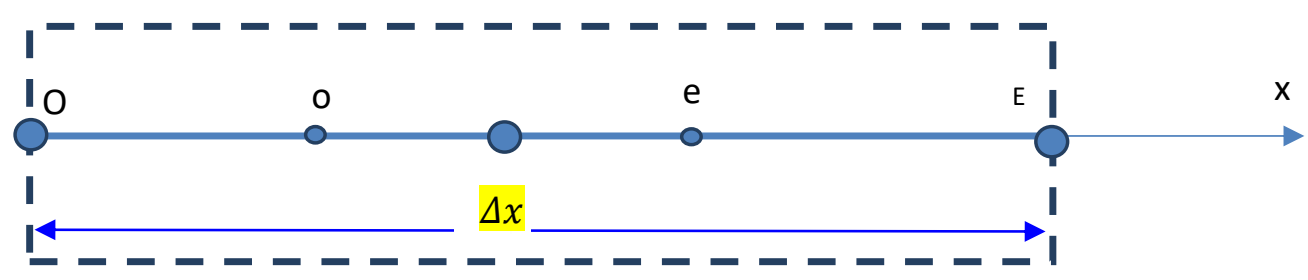

Figure 1. Schematic representation of Finite Difference Approach

Thus the discretized equations are given by:

$A_{p} p_{p}+A_{O} p_{O}+A_{E} p_{E}+S_{c}=0$

Where for the Reynolds equation (1) with Gümbel [11] condition for cavitation effect: 


$$
\left\{\begin{array}{l}
A_{P}=-\frac{h_{o}^{3}+h_{e}^{3}}{\Delta x} \\
A_{O}=\frac{h_{o}^{3}}{\Delta x} \\
A_{E}=\frac{h_{e}^{3}}{\Delta x} \\
S C=-6 \mu U\left(h_{e}-h_{o}\right)
\end{array}\right.
$$

And for the modified Reynolds equation (6):

$$
\left\{\begin{array}{l}
\mathrm{A}_{\mathrm{P}}=-2 \frac{\mathrm{h}_{\mathrm{O}}^{3}+\mathrm{h}_{\mathrm{E}}^{3}+2 \mathrm{~h}_{P}^{3}}{\Delta x} \phi_{P}-6 \mu \mathrm{U}\left(1-\phi_{P}\right) \\
\mathrm{A}_{\mathrm{O}}=2 \frac{\mathrm{h}_{\mathrm{O}}^{3}+\mathrm{h}_{P}^{3}}{\Delta x} \phi_{O}+6 \mu \mathrm{U}\left(1-\phi_{O}\right) \\
\mathrm{A}_{\mathrm{E}}=2 \frac{\mathrm{h}_{\mathrm{E}}^{3}+\mathrm{h}_{P}^{3}}{\Delta x} \phi_{E} \\
\mathrm{Sc}=-6 \mu \mathrm{U}\left(\mathrm{h}_{\mathrm{e}}-\mathrm{h}_{\mathrm{o}}\right)
\end{array}\right.
$$

To validate the numerical model used in our Hydrodynamic lubrication simulations, we refer to the work of Fowell et al. $[9,10]$ that studied the effects of textured surfaces. The analytical formulas proposed in this work allow simple but at the same time precise calculation of the pressure distribution across a textured surface. Cavitation zones are also located in the contact using a formulation based on mass conservation.

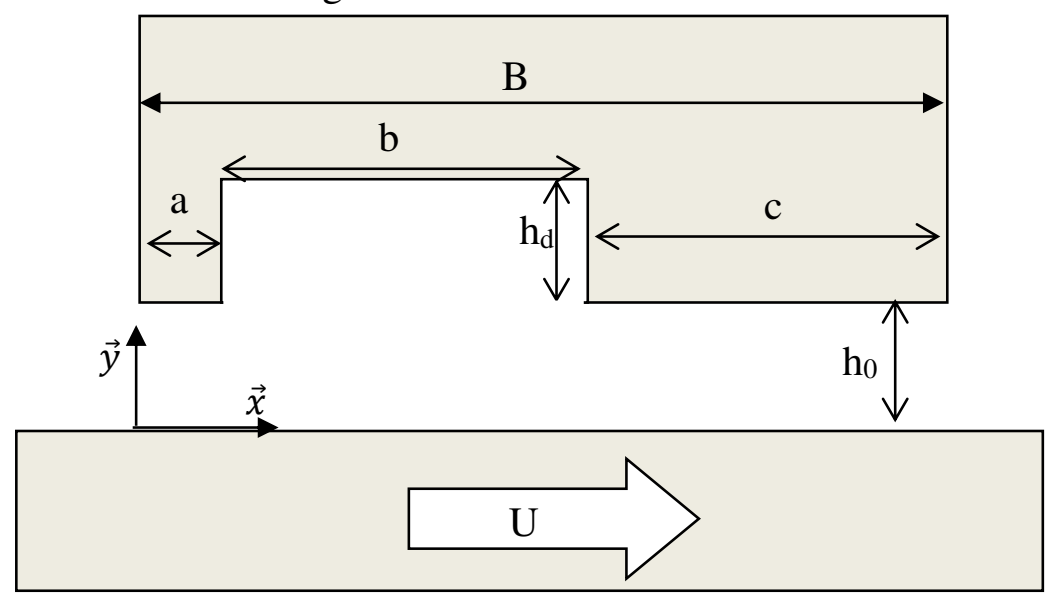

Figure 2. Schematic representation of the textured pad [9]

The geometry proposed by Fowell [9] in figure 2 consists of a slot located on the stationary surface of a parallel faced pad. Thereby, in the divergent-convergent zone with the operating conditions (Table 1), cavitation could occur. 


\begin{tabular}{|l|l|}
\hline Parameter & Numerical value \\
\hline Pad length & $\mathrm{B}=20 \mathrm{~mm}$ \\
\hline Inlet length & $\mathrm{a}=4 \mathrm{~mm}$ \\
\hline Slot length & $\mathrm{b}=6 \mathrm{~mm}$ \\
\hline Outlet length & $\mathrm{c}=10 \mathrm{~mm}$ \\
\hline Minimum film thickness & $\mathrm{h}_{0}=1 \mathrm{micron}$ \\
\hline Depth of pocket & $\mathrm{h}_{\mathrm{d}}=5 \mathrm{micron}$ \\
\hline Velocity & $\mathrm{U}=1 \mathrm{~m} / \mathrm{s}$ \\
\hline Dynamic viscosity & $\mu=0.01 \mathrm{~Pa} . \mathrm{s}$ \\
\hline Ambient pressure & $\mathrm{p}_{0}=0.1 \mathrm{MPa}$ \\
\hline Cavitation pressure & $\mathrm{p}_{\mathrm{cav}}=0 \mathrm{MPa}$ \\
\hline
\end{tabular}

Table 1. Geometry and operating conditions of the textured pad [9].

The boundary conditions are given by: at " $x=0 ", " p(0)=p_{0}$ " and at " $x=B ", " p(B)=p_{0} "$.

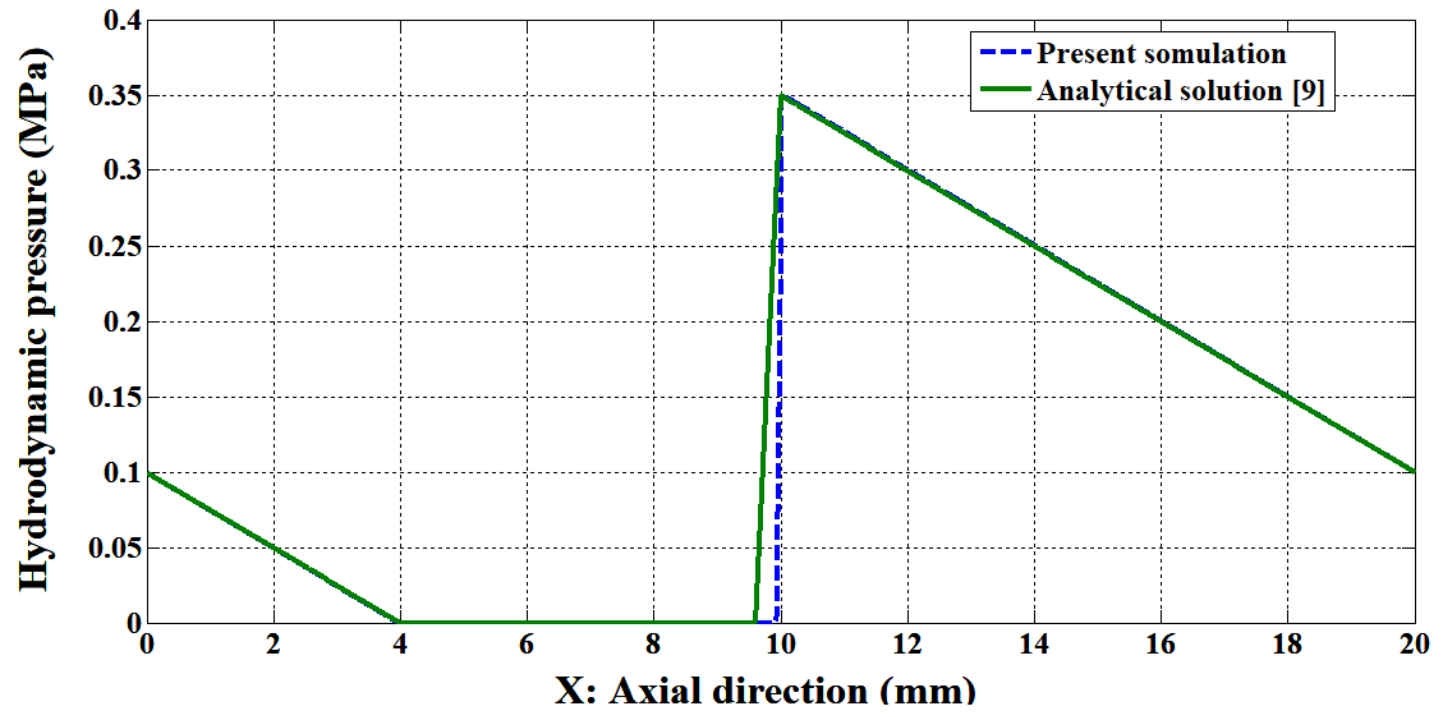

Figure 3. Comparison between present model and results of [9]

Comparing simulations of the present model and the analytical results [9], figure 3 confirms a good agreement between the pressure distributions. However, the figure shows that the difference is mainly caused by the discontinuous domain of the film thickness $\mathrm{h}(\mathrm{x})$. Indeed, the large mesh size of the geometry impacts the derivative accuracy of the function $\mathrm{h}(\mathrm{x})$. 


\subsection{Computing different film thickness distributions}

A single and unique film thickness investigation can now be initiated to generate the same hydrodynamic pressure given by the Reynolds equation solution. Let us assume at the beginning, the existence of two roots for the equation (2), $\mathrm{H}_{1}$ and $\mathrm{H}_{2}$. Thus the equation (2) becomes:

$\left\{\begin{array}{l}\frac{H_{1}{ }^{3}}{6 \mu U} \frac{d p}{d x}=H_{1}-h^{*} \\ \frac{H_{2}{ }^{3}}{6 \mu U} \frac{d p}{d x}=H_{2}-h^{*}\end{array}\right.$

where: $H_{1}(x)$ is equal to the film thickness $h(x)$ initially given.

In this section, we aim to check if $\mathrm{H}_{2}(\mathrm{x})$ is equal to $\mathrm{H}_{1}(\mathrm{x})$ whatever $\mathrm{x}$ between 0 and $\mathrm{L}$.

By subtracting equations (10.1) and (10.2), we find:

$$
\left(H_{2}{ }^{3}-H_{1}{ }^{3}\right) \frac{d p}{d x}-6 \mu U\left(H_{2}-H_{1}\right)=0
$$

Thus the equivalent equation to resolve with $\mathrm{H}_{2}$ as unknown thickness is given by:

$$
\left(H_{2}{ }^{2}+H_{1} H_{2}+{H_{1}}^{2}\right) \frac{d p}{d x}-6 \mu U=0 \quad \text { where } H_{1} \neq H_{2}
$$

To find the roots of equation (12), the algorithm below is used for each $\mathrm{x}$ between 0 and L:

if: $0<\frac{d p}{d x}<\frac{8 \mu U}{H_{1}{ }^{2}}$ then $H_{2}(x)=\frac{-H_{1}(x)}{2}+\sqrt{\frac{6 \mu U}{\frac{d p}{d x}}-\frac{3}{4} H_{1}{ }^{2}(x)}$

else: $\quad H_{2}(x)=H_{1}(x)$ 
Equation (13) leads to the following condition regarding the unicity of the film thickness:

$$
\frac{\mathrm{dp}}{\mathrm{dx}} \geq \frac{8 \mu \mathrm{U}}{\mathrm{H}_{1}{ }^{2}} \text { or } \frac{\mathrm{dp}}{\mathrm{dx}} \leq 0 \quad \text { for each "x" between "0" and "L" }
$$

It is important to note that, when the condition (15) is not verified, all the roots film thickness $\mathrm{H}_{2}$ could be combined to the initial film thickness $\mathrm{H}_{1}$, and generate a new film thickness $\mathrm{h}(\mathrm{x})$ with the equation:

$$
h(\mathrm{x})=\alpha(\mathrm{x}) H_{1}(\mathrm{x})+(1-\alpha(\mathrm{x})) H_{2}(\mathrm{x})
$$

where: $\alpha$ is an entire coefficient of geometry depending on the coordinate $\mathrm{x}$ and is equal to 1 or 0 , and $H_{1}(x)$ the initial film thickness and $H_{2}(x)$ the roots film thickness.

Engineers could choose the parameter $\boldsymbol{\alpha}(\mathbf{x})$ to define a new surface generating the same hydrodynamic pressure. Later in this paper, an investigation is performed to demonstrate how far the pressure is similar by considering the cavitation effect.

\section{Applications}

\subsection{Different bearing geometry: without cavitation effect}

To explain carefully this new theory, an example of a commonly known bearing "Sloping surface" is studied as described in figure 4.

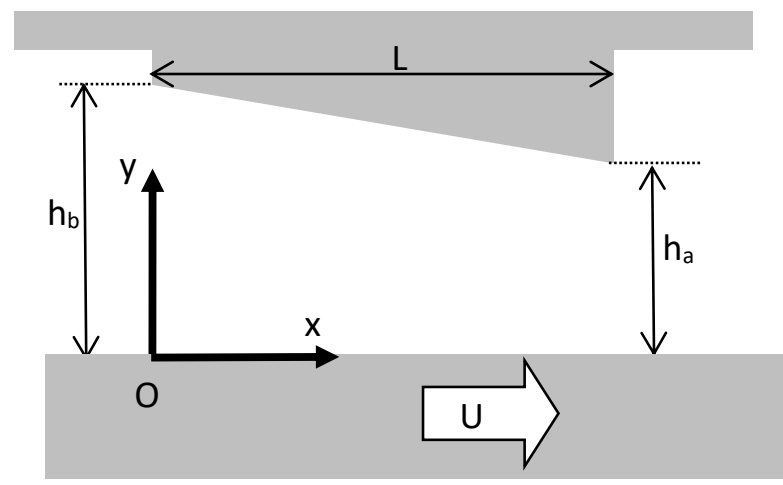

Figure 4. The bearing geometry "sloping surface" 
Figure 4 shows the flow between two non-parallel flat plates of infinite width according to $(\mathrm{Oz})$ and height difference at the ends $h_{a}$ and $h_{b}$ with a length $L$. The lower plate is driven by a uniform translation movement of speed $\mathrm{U}$, the upper plate is stationary and inclined in the (xOy) plane by a very small constant angle.

The guessed initial film thickness, in this case, is given by the following equation:

$$
H_{1}(x)=h_{a}+\frac{\left(h_{b}-h_{a}\right)}{L}(L-x)
$$

By assuming the following data: $L=20 \mathrm{~mm}, \mathrm{~h}_{b}=0.008 \mathrm{~mm}, \mathrm{~h}_{\mathrm{a}}=0.002 \mathrm{~mm}, \mu=0.01$ Pa.s, $\mathrm{U}=200 \mathrm{~mm} / \mathrm{s}$. With those operational conditions, the current bearing geometry generates the hydrodynamic pressure shown in figure 5. A comparison between the finite difference method used in the previous section and the analytical result was performed and the numerical algorithm was easily validated.

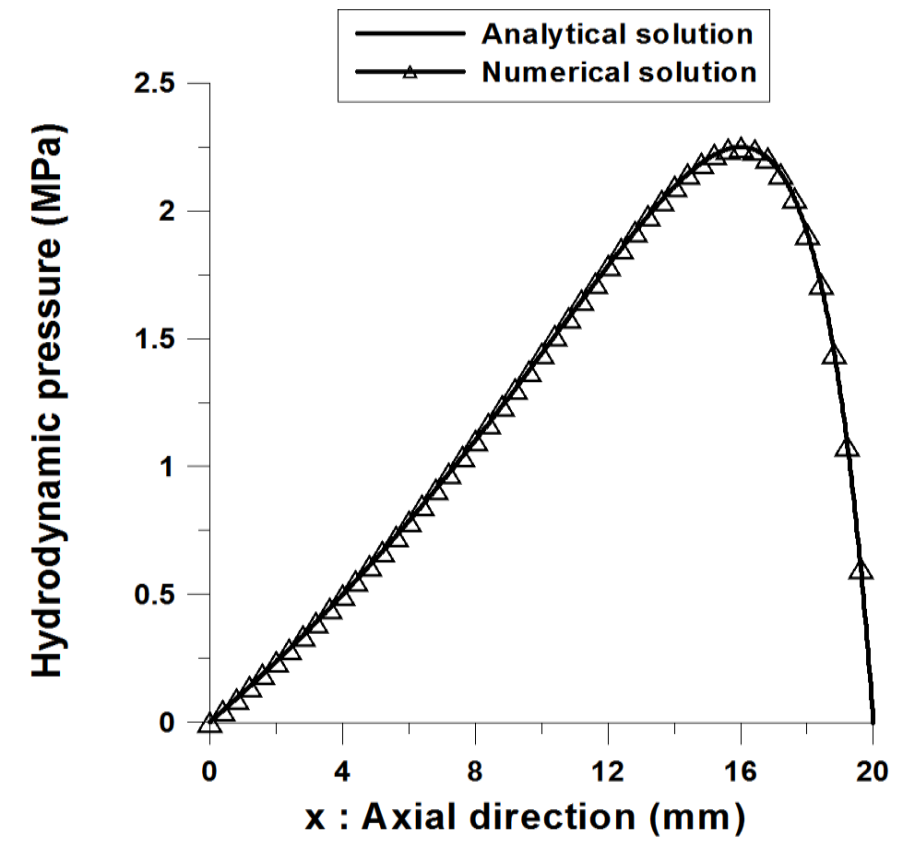

Figure 5. Hydrodynamic pressure for inclined surface bearing

Figure 6 proposes the different configurations that engineers could make among two solutions: $\mathrm{H}_{1}$ and $\mathrm{H}_{2}$ to design an appropriate geometry for the load support, keeping 
the same hydrodynamic lifting force and the same flow rate. Indeed, for illustrative purposes, all the shapes shown in figure 7 could generate the same performance by only combining the initial and second film thickness within the parameter $\alpha(\mathrm{x})$ in the equation (16). This approach is a very convenient tool that allows engineers to choose the optimal surface to guide machinery components.
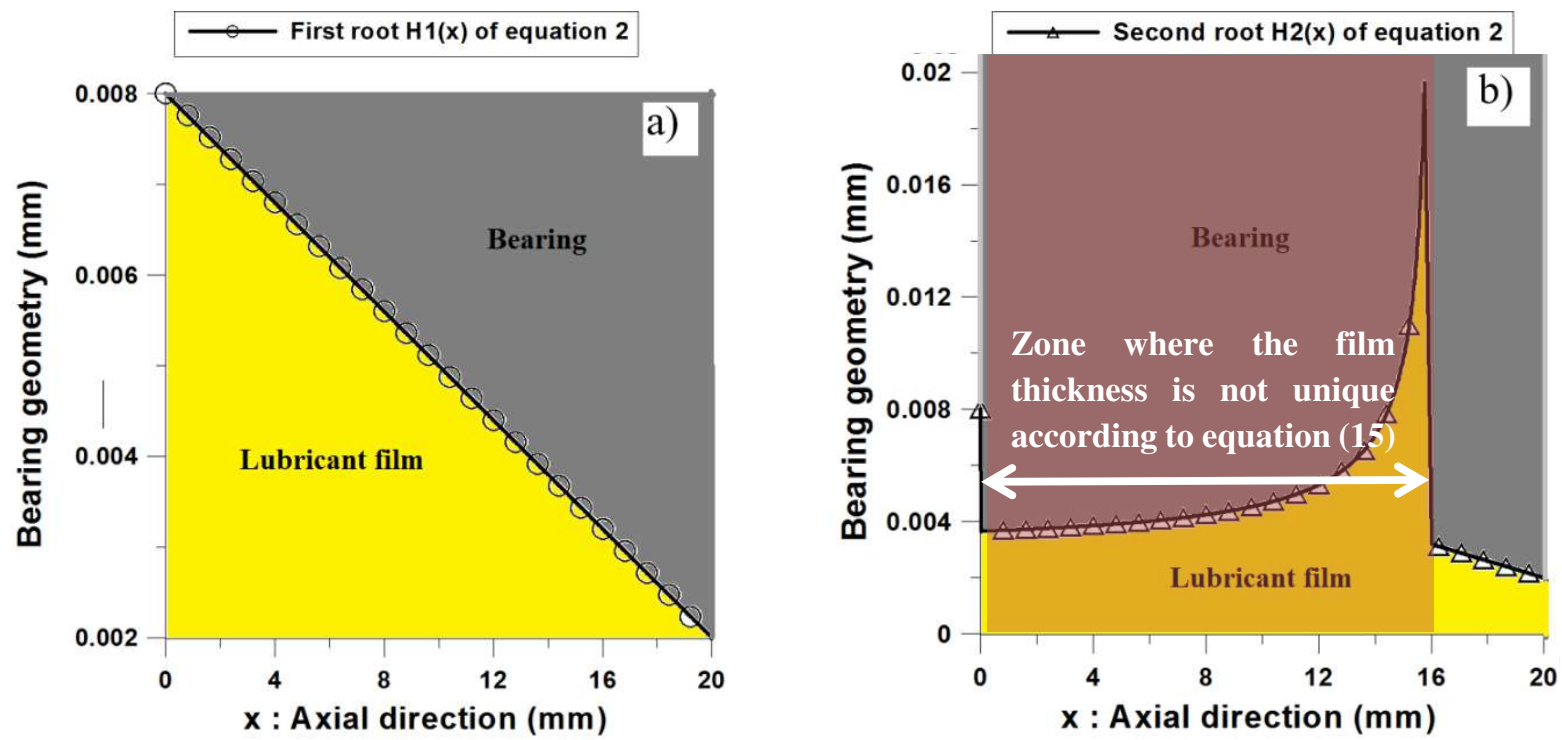

Figure 6. The film thicknesses roots: a) the initial film thickness $\mathrm{H}_{1}(\mathrm{x})$, b) the second film thickness computed from equations (13) and (14)
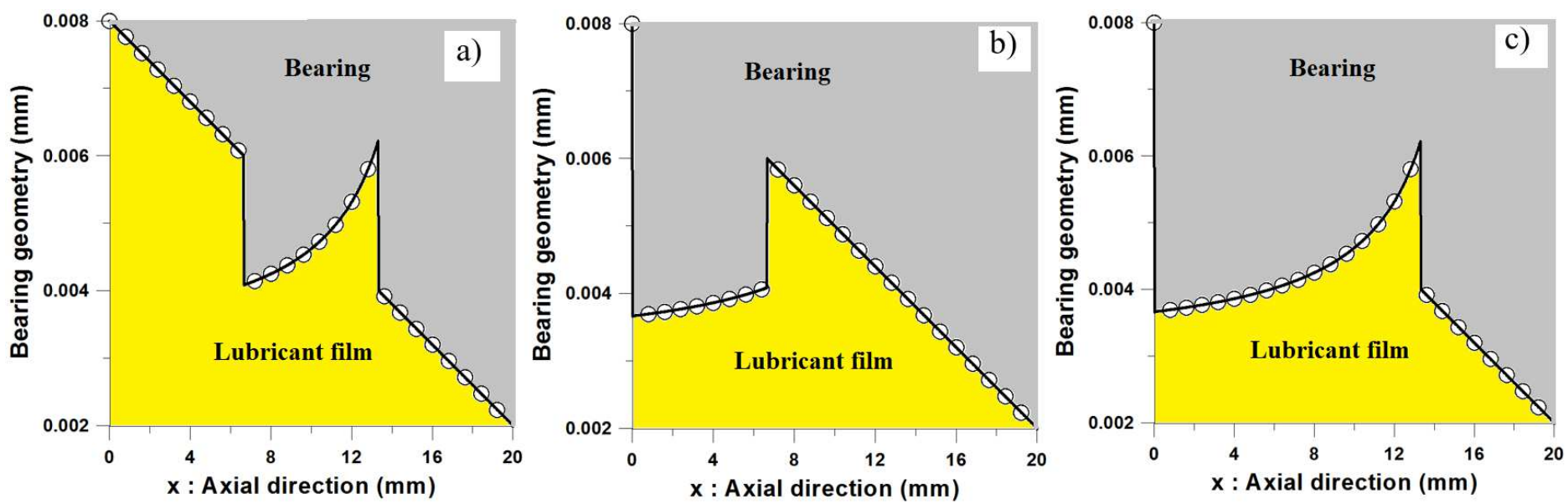

Figure 7. Examples of different bearing shape, a) shape\#1, b) shape\#2, c) shape\#3 
It is relevant to confirm that with all the three bearing surface shape \#1, \#2, and \#3, the same hydrodynamic pressure is generated as shown in figure 8 , and the same flow rate as demonstrated in figure 9.

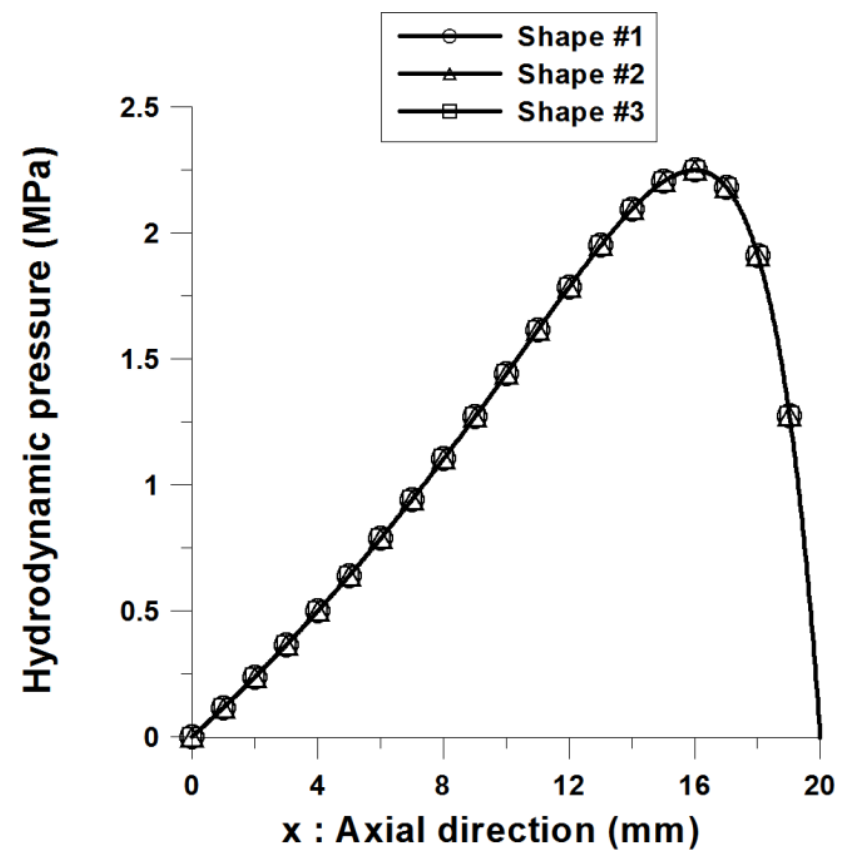

Figure 8 . Hydrodynamic pressure with different bearing geometry

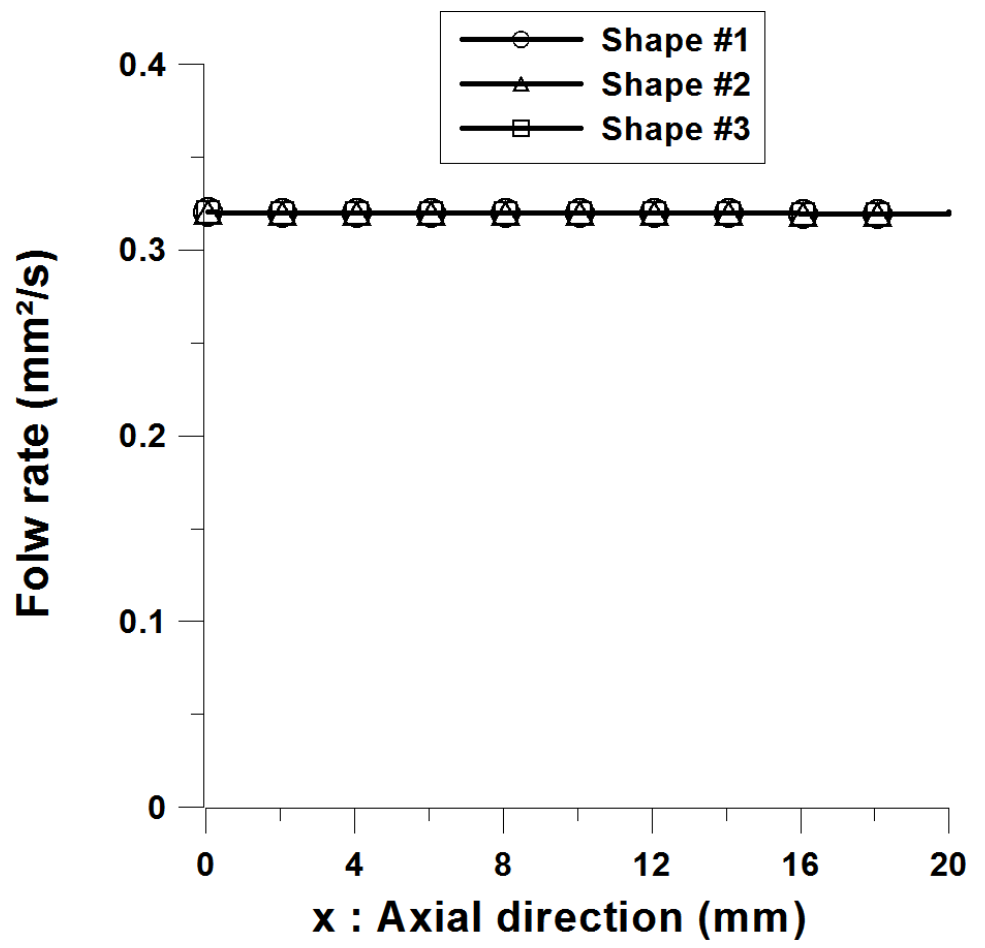

Figure 9. Flow rate conservation with different bearing geometry 
It is also important to note that the frictional force difference between the three bearing surfaces is slightly regular. Thus with shape\#1, the friction force per length is about $12.98 \mathrm{~N} / \mathrm{m}$, shape\#2 is $13.16 \mathrm{~N} / \mathrm{m}$, and $13.17 \mathrm{~N} / \mathrm{m}$ for shape\#3.

Thus the designers need to perform several iterations by changing geometry to maintain the same lifting force and flow rate and minimizing the viscous friction effect.

\subsection{Micro-textured surfaces}

After confirming the existence of different film thicknesses generating similar hydrodynamic pressure in the case of bearing with macro shaped geometry, this section presents a second application in the lubricated contact by considering micro-textured surfaces.

This part aims to find all micro-textured surfaces providing the same lifting force by considering the phenomena resulting from the convergent-divergent domain, especially the cavitation effect.

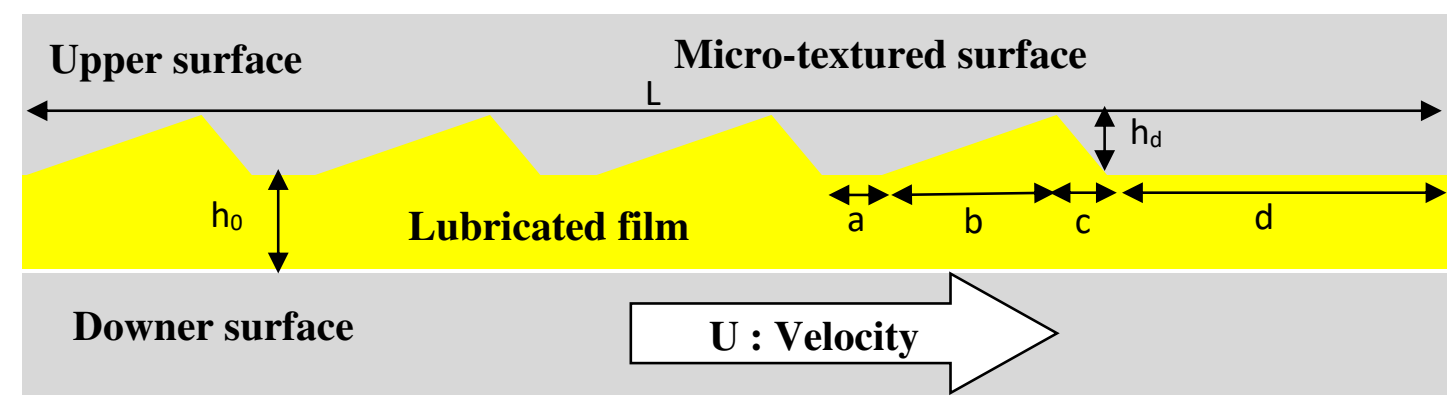

Figure 10. The micro-textured bearing geometry.

Figure 10 illustrates the considered micro-textured surface with the operational parameters in table 2 . 


\begin{tabular}{|l|l|}
\hline \multirow{2}{*}{ Parameter } & Numerical value \\
\hline Upper surface length & $\mathrm{L}=100 \mathrm{~mm}$ (Non cavitated case) \\
\cline { 2 - 2 } & $\mathrm{L}=76 \mathrm{~mm}$ (Cavitated case) \\
\hline Inlet length of cell texture & $\mathrm{a}=4 \mathrm{~mm}$ \\
\hline The first length of cell texture & $\mathrm{b}=6 \mathrm{~mm}$ \\
\hline The second length of cell texture & $\mathrm{c}=10 \mathrm{~mm}$ \\
\hline Outlet length of cell texture & $\mathrm{d}=24 \mathrm{~mm}$ (Non cavitated case) \\
\cline { 2 - 2 } & $\mathrm{d}=0 \mathrm{~mm}$ (Cavitated case) \\
\hline Texture depth & $\mathrm{h}_{\mathrm{d}}=5 \mathrm{micron}$ \\
\hline Separating space film thickness & $\mathrm{h}_{0}=5 \mathrm{micron}$ \\
\hline Texture density & $\mathrm{N}=4$ \\
\hline Velocity & $\mathrm{U}=1 \mathrm{~m} / \mathrm{s}$ \\
\hline Dynamic viscosity & $\mu=0.01 \mathrm{~Pa} . \mathrm{s}$ \\
\hline Ambient pressure & $\mathrm{p}_{0}=0.1 \mathrm{MPa}$ \\
\hline Cavitation pressure & $\mathrm{p}_{\mathrm{cav}}=0 \mathrm{MPa}$ \\
\hline Node number & $\mathrm{N}=1000 \mathrm{Nodes}$ \\
\hline
\end{tabular}

Table 2. Geometry and operating conditions of the microtextured surface.

\subsubsection{First case: $\mathrm{L}=100 \mathrm{~mm}, \mathrm{~d}=24 \mathrm{~mm}$ (without cavitation effect)}

A micro-textured surface is considered with an initial film thickness $\mathrm{H}_{1}(\mathrm{x})$ given in figure 10 .

This study is performed throughout three steps: 1) computing the hydrodynamic pressure " $p(x)$ " with the guessed initial film thickness " $\mathrm{H}_{1}(\mathrm{x})$ " and resolving the Reynolds equation (1), 2) using the equations (13) and (14) to find the roots film thickness $\mathrm{H}_{2}(\mathrm{x}), 3$ ) comparing hydrodynamic pressures " $\mathrm{p}(\mathrm{x})$ " corresponding to the film thickness $\mathrm{H}_{1}(\mathrm{x})$ and $\mathrm{H}_{2}(\mathrm{x})$ with modified Reynolds equation.

Step 1: The hydrodynamic pressure corresponding to the initial film thickness $H_{1}(x)$ :

According to the discretized equation (6), the Reynolds equation is resolved. Figure 11 shows the hydrodynamic pressure " $\mathrm{p}(\mathrm{x})$ " corresponding to the initial film thickness $\mathrm{H}_{1}(\mathrm{x})$. 


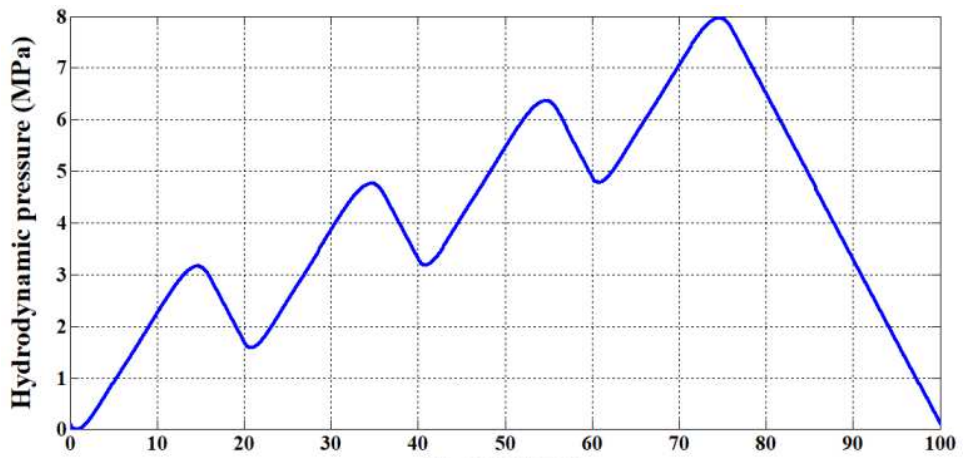

Figure 11. Hydrodynamic pressure according to the initial film thickness $\mathrm{H}_{1}(\mathrm{x})$

Step 2: The second film thickness roots $\mathrm{H}_{2}(x)$ :

By using the equations (14) and (15), the second film thickness $\mathrm{H}_{2}(\mathrm{x})$ is computed. Figure 12 shows the big difference between the first film thickness $\mathrm{H}_{1}(\mathrm{x})$ and $\mathrm{H}_{2}(\mathrm{x})$. It is important to underline that both film thicknesses generate the same hydrodynamic pressure $\mathrm{p}(\mathrm{x})$.
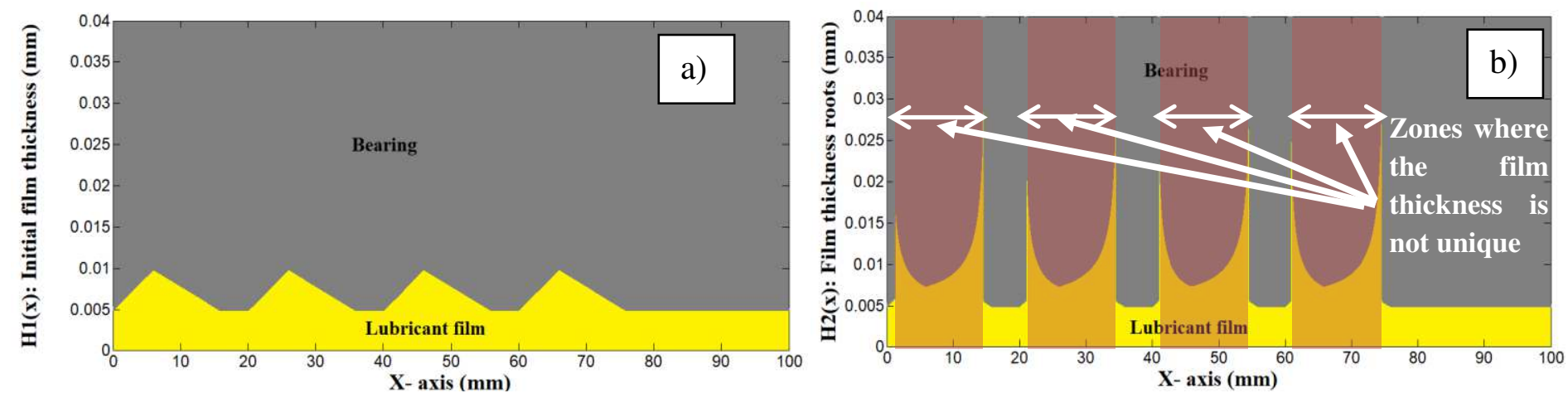

Figure 12. The film thicknesses roots without cavitation effect: a) the initial film thickness $\mathrm{H}_{1}(\mathrm{x})$, b) the second film thickness computed from equations (13) and (14)

Step 3: Comparing the hydrodynamic pressure for each film thickness

According to numerical results of step 2, figure 13 confirms the similar hydrodynamic pressure provided by differents film thicknesses $\mathrm{H}_{1}(\mathrm{x})$ and $\mathrm{H}_{2}(\mathrm{x})$. 


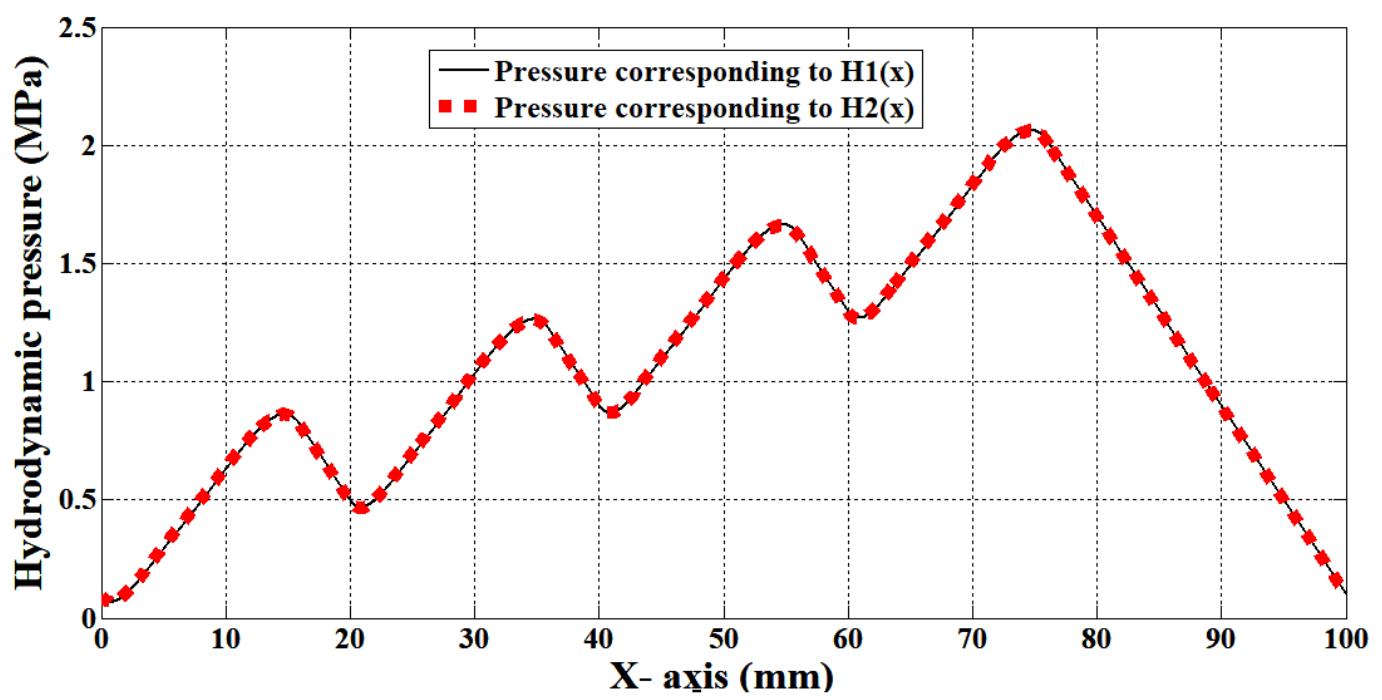

Figure 13. Hydrodynamic pressure with the different micro-textured surface without cavitation

\subsubsection{Second case: $\mathrm{L}=76 \mathrm{~mm}, \mathrm{~d}=0 \mathrm{~mm}$ (with cavitation effect)}

To investigate the cavitation effect on the second film thickness $\mathrm{H}_{2}(\mathrm{x})$, this section aims to study microtextured surface generating cavitated zone with $\mathrm{L}=76 \mathrm{~mm}$ and $\mathrm{d}=0 \mathrm{~mm}$ as described in figure 10. This analysis is performed throughout three steps: 1) resolving the Reynolds equation (1) to find the hydrodynamic pressure " $p(x)$ " with the initial film thickness " $\mathrm{H}_{1}(\mathrm{x})$ ", 2) using the equations (13) and (14) to compute the second film thickness $\mathrm{H}_{2}(\mathrm{x}), 3$ ) comparing hydrodynamic pressures " $\mathrm{p}(\mathrm{x})$ " corresponding to the film thickness $\mathrm{H}_{1}(\mathrm{x})$ and $\mathrm{H}_{2}(\mathrm{x})$.

Step 1: The hydrodynamic pressure corresponding to the initial film thickness $H_{1}(x)$, with Gümbel [11] cavitation condition.

Reynolds equation is resolved by considering the Gümbel conditions [11] given in the equation (5). Figure 11 shows the hydrodynamic pressure " $p(x)$ " corresponding to the initial film thickness $\mathrm{H}_{1}(\mathrm{x})$, where the existence of the cavitated zones is highlighted. 


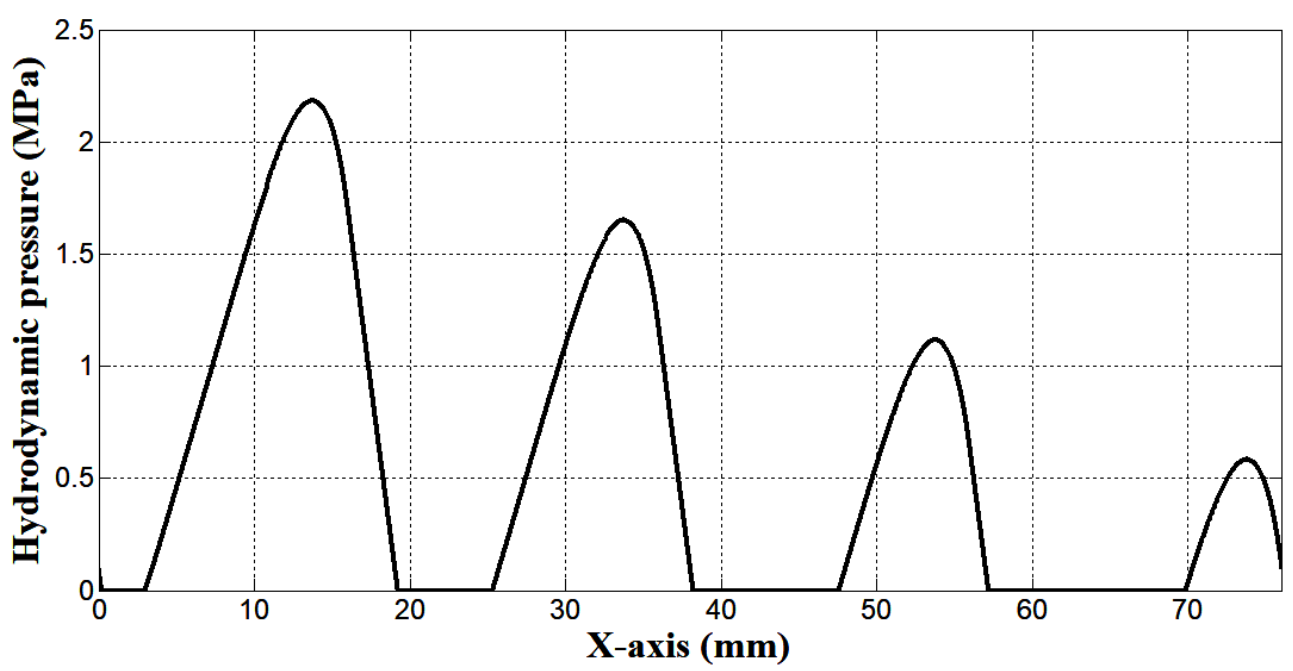

Figure 14. Hydrodynamic pressure with the initial film thickness $\mathrm{H}_{1}(\mathrm{x})$

Step 2: The film thickness roots $H_{2}(x)$ :

The second film thickness $\mathrm{H}_{2}(\mathrm{x})$ is computed from equations (14) and (15) by using the hydrodynamic pressure corresponding to the initial film thickness $\mathrm{H}_{1}(\mathrm{x})$. Figure 15 demonstrates the impact of the cavitation on the second film thickness $\mathrm{H}_{2}(\mathrm{x})$. Indeed, the initial film thickness $\mathrm{H}_{1}(\mathrm{x})$ is nearly equal to the second $\mathrm{H}_{2}(\mathrm{x})$ except in the vicinity of crossing cavitated to the non-cavitated zone.
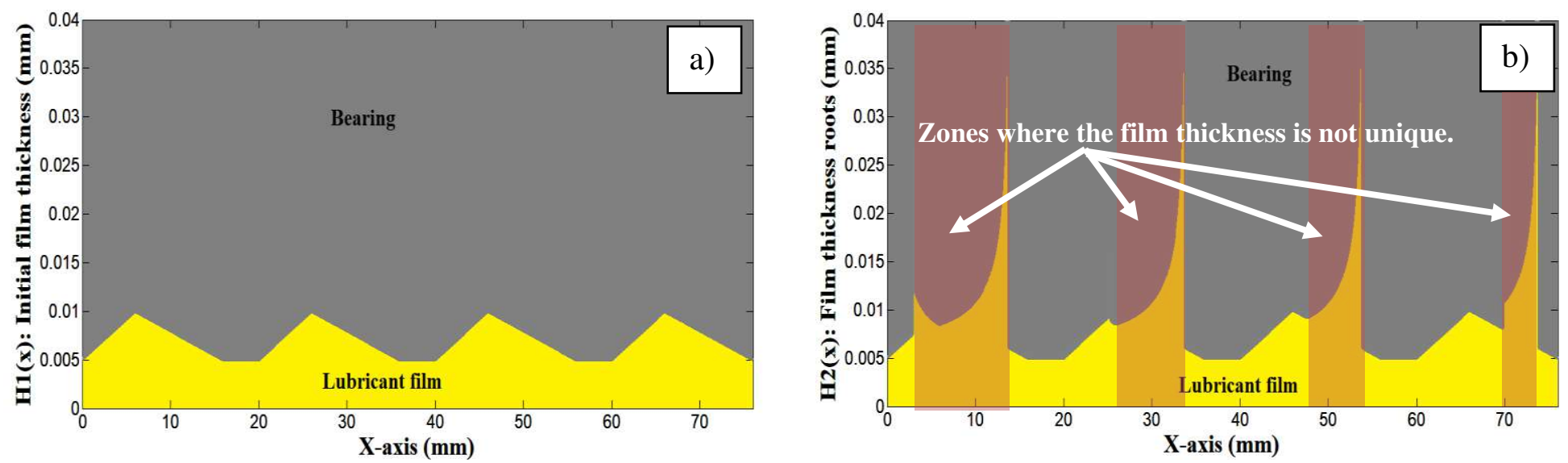

Figure 15. The film thicknesses roots with cavitation effect: a) the initial film thickness $\mathrm{H}_{1}(\mathrm{x})$, b) the second film thickness computed from equations (13) and (14)

Step 3: Comparing the hydrodynamic pressure for each film thickness (with modified Renolds equation) 
To compare the hydrodynamic pressure generated with the film thicknesses: the initial $\mathrm{H}_{1}(\mathrm{x})$ and the second $\mathrm{H}_{2}(\mathrm{x})$, the modified Reynolds equation was resolved of both thicknesses by considering the mass conservation instead of the Gümbel model [11] according to equation (5).

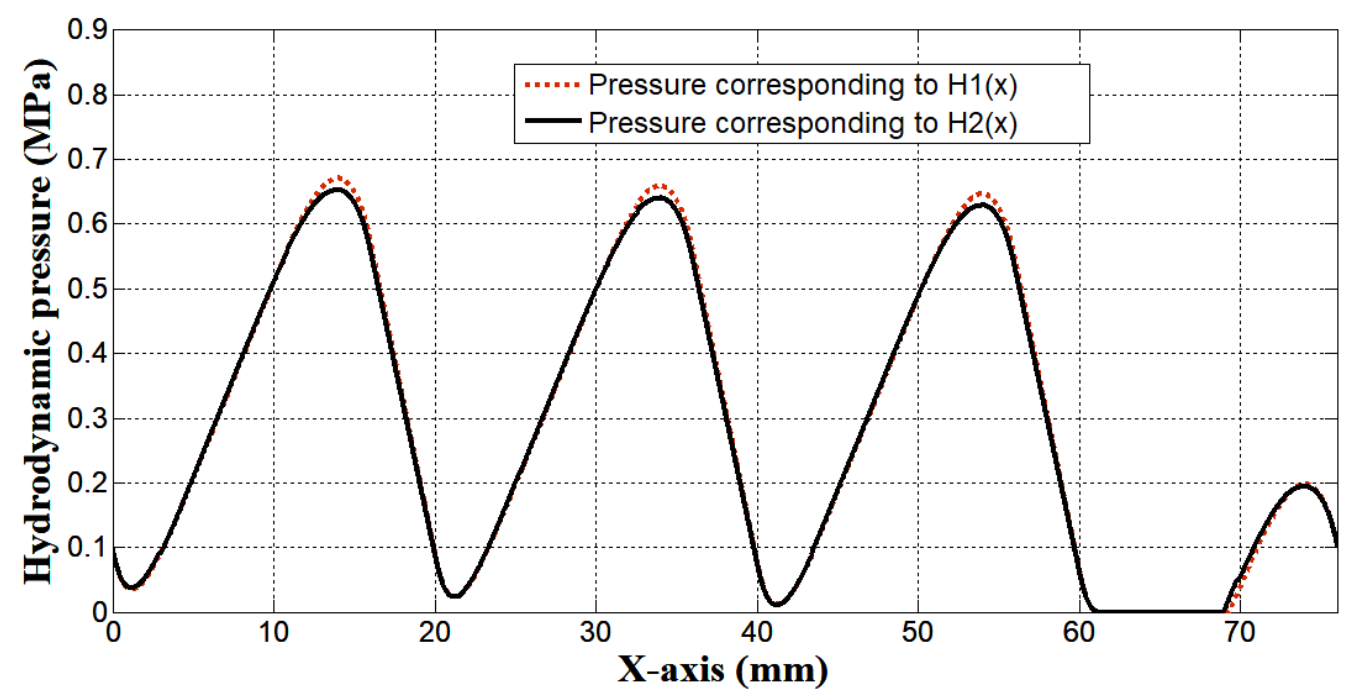

Figure 16. Comparison between the hydrodynamic pressure provided by initial film thickness $\mathrm{H}_{1}(\mathrm{x})$ and the second film thickness $\mathrm{H}_{2}(\mathrm{x})$.

Figure 16 confirms a slight difference in the hydrodynamic pressure corresponding to the film thicknesses $\mathrm{H}_{1}(\mathrm{x})$ and $\mathrm{H}_{2}(\mathrm{x})$, despite the big difference with the hydrodynamic pressure given by the initial film thickness $\mathrm{H}_{1}(\mathrm{x})$ computed according to the Gümbel model [11]. Therefore, it is also relevant to underline that the same initial film thickness $\mathrm{H}_{1}(\mathrm{x})$ gives two differents hydrodynamic pressures with mass conservation according to modified Reynolds equation (6) and with the Gümbel cavitation model (5).

\subsubsection{Effect of separating space film thickness: $\mathrm{h}_{0}$.}

It is well known that the gap that separates lubricated surfaces affects significantly the hydrodynamic pressure. Thus, this section aims to prove the effectiveness of such an operational parameter on the second film thickness by considering the cavitation effect. 
To perform this investigation, the similar micro-textured surface is considered with $\mathrm{L}=76 \mathrm{~mm}$ and $\mathrm{d}=0 \mathrm{~mm}$ as described in figure 10 and three differents separating gap are designed as follow: Case\# 1 with $\mathrm{h}_{0}=5$ microns, Case\# 2 with $\mathrm{h}_{0}=1$ microns and Case\# 3 with $\mathrm{h}_{0}=10$ micons.
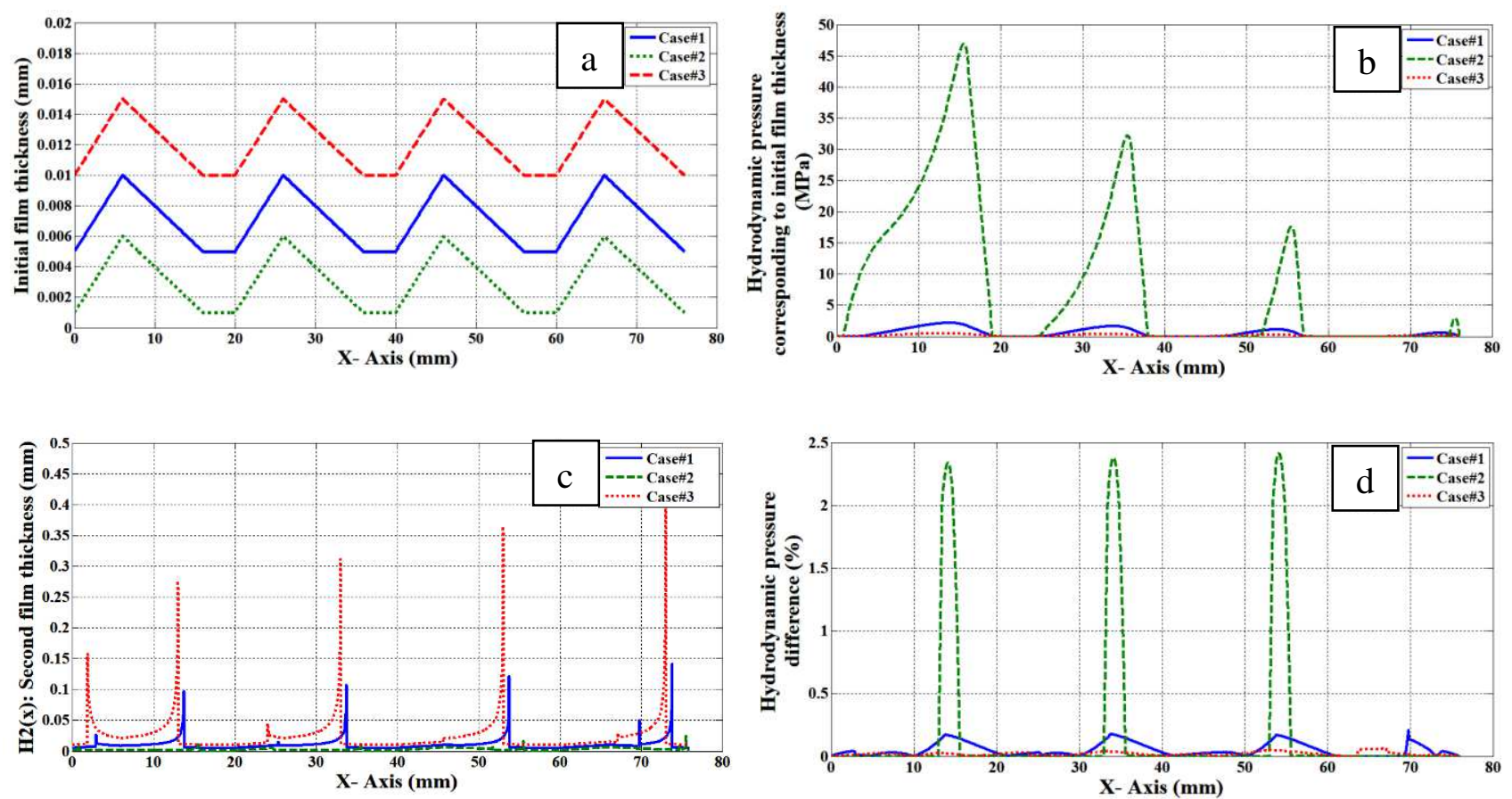

Figure 17. Comparison between three separating gaps: a) initial film thickness $\mathrm{H}_{1}(\mathrm{x})$, b) Hydrodynamic pressure corresponding to $\mathrm{H}_{1}(\mathrm{x})$ with Gümbel model, c) Second film thickness $\mathrm{H}_{2}(\mathrm{x})$, d) Difference between hydrodynamic pressure computed from $\mathrm{H}_{1}(\mathrm{x})$ and $\mathrm{H}_{2}(\mathrm{x})$ with modified Reynolds equation.

Figure 17 shows the impact of the gap between lubricated surfaces. As long as surfaces are close, as the hydrodynamic pressure is high and, the deviation between the hydrodynamic pressure produced by the second thickness is large compared to that generated by the initial thickness. Although the differences do not exceed $2 \%$ between pressure, the deviation maximum is located at the cavitation zone crossing to the noncavitated zone. Consequently, the proposed method for generating a second film thickness is applicable for any spacing gap between lubricated surfaces. 


\subsection{Rough surfaces}

In general, the roughness surface is the relevant parameter that significantly affects the lubricated contact. Previous works have demonstrated that the arithmetic roughness Ra, the standard deviation $\sigma$, the Kurtosis and Skewness parameters Ku, and Sk respectively define the topography surface capacity to characterize tribological behavior of surfaces. One of the pillar methods to find the hydrodynamic pressure for each rough surfaces is based on the stochastical approach with Patir and Cheng flow factors [7]. This stochastic method defines pressure as a function of the averaged film thicknesses ratio by the standard deviation roughness $h_{0} / \sigma$.

The main subject of this section is to prove with different surface topography parameters: $\mathrm{Ra}, \mathrm{Ku}$, and Sk could generate the same hydrodynamic pressure. It is also very relevant to demonstrate that with different standard deviation $\sigma$ the hydrodynamic pressure could be maintained, thus the adimensional film thickness $\mathrm{h}_{0} / \sigma$ is not sufficient to define the Hydrodynamic or Elasto-hydrodynamic regime.

Table 3 gives the initial film thickness (respectively the initial surface roughness), and the second film thickness is given by equations (13) and (14), with operational parameters as described in table 1 with a lubricated length $\mathrm{L}=76 \mathrm{~mm}$ and separating gap $\mathrm{h}_{0}=1$ microns.

Standard deviation ( so-called Root Mean Square RMS) $\sigma$, the Arithmetic Roughness Ra, Kurtosis Ku, and Skewness Sk are computed for each film thickness "H" as follow: 


$$
\left\{\begin{array}{l}
R(x)=H(x)-h_{0} \\
\bar{R}=\frac{1}{N} \sum_{i=1}^{N} R_{i}=0 \text { (Assumption of randomized signal) } \\
\sigma=\sqrt{\frac{1}{N} \sum_{i=1}^{N}\left(R_{i}-\bar{R}\right)^{2}} \\
S k=\frac{1}{\sigma^{3} N} \sum_{i=1}^{N}\left(R_{i}-\bar{R}\right)^{3} \\
K u=\frac{1}{\sigma^{4} N} \sum_{i=1}^{N}\left(R_{i}-\bar{R}\right)^{4}
\end{array}\right.
$$

where: $\mathrm{R}$ is the roughness function represented in the realistic case with a randomized signal, and $\mathrm{N}$ is the total node number.

\begin{tabular}{|l|c|c|c|c|}
\hline \multirow{2}{*}{ Surface code } & \multicolumn{3}{|c|}{ Surface topography parameters } \\
\cline { 2 - 5 } & Arithmetic & Standard & Kurtosis: & Skewness: \\
& roughness: Ra & deviation: $\sigma$ & $\mathrm{Ku}$ & Sk \\
\hline Initial film thickness: Rough\#1 & $1,00 \times 10^{-3} \mathrm{~mm}$ & $338,08 \times 10^{-6} \mathrm{~mm}$ & 132,84 & 34,82 \\
\hline Second film thickness: Rough\#2 & $1,26 \times 10^{-3} \mathrm{~mm}$ & $1,53 \times 10^{-3} \mathrm{~mm}$ & 96,53 & 10,22 \\
\hline
\end{tabular}

Table 3. Initial and second roughnesses corresponding to film thickness $\mathrm{H}_{1}(\mathrm{x})$ and $\mathrm{H}_{2}(\mathrm{x})$ respectively.

Figure 18 shows numerical simulation by considering randomized surface as an initial surface roughness with a separating gap $h_{0}=1$ microns, with the operational parameters in table 2, the second film thickness $\mathrm{H}_{2}(\mathrm{x})$ is deduced from equations (13) and (14) as given in figure 18.a. Before computing the film thickness $\mathrm{H}_{2}(\mathrm{x})$, a post-processing step is important: computing the hydrodynamic pressure generated by the initial film thickness $\mathrm{H}_{1}(\mathrm{x})$ throughout resolving equation (1) and using Gümbel cavitation model [11]. 
To compare the accuracy of simulations, the hydrodynamic pressure produced by both film thicknesses $\mathrm{H}_{1}(\mathrm{x})$ and $\mathrm{H}_{2}(\mathrm{x})$ is computed by the Modified Reynolds equation (6).
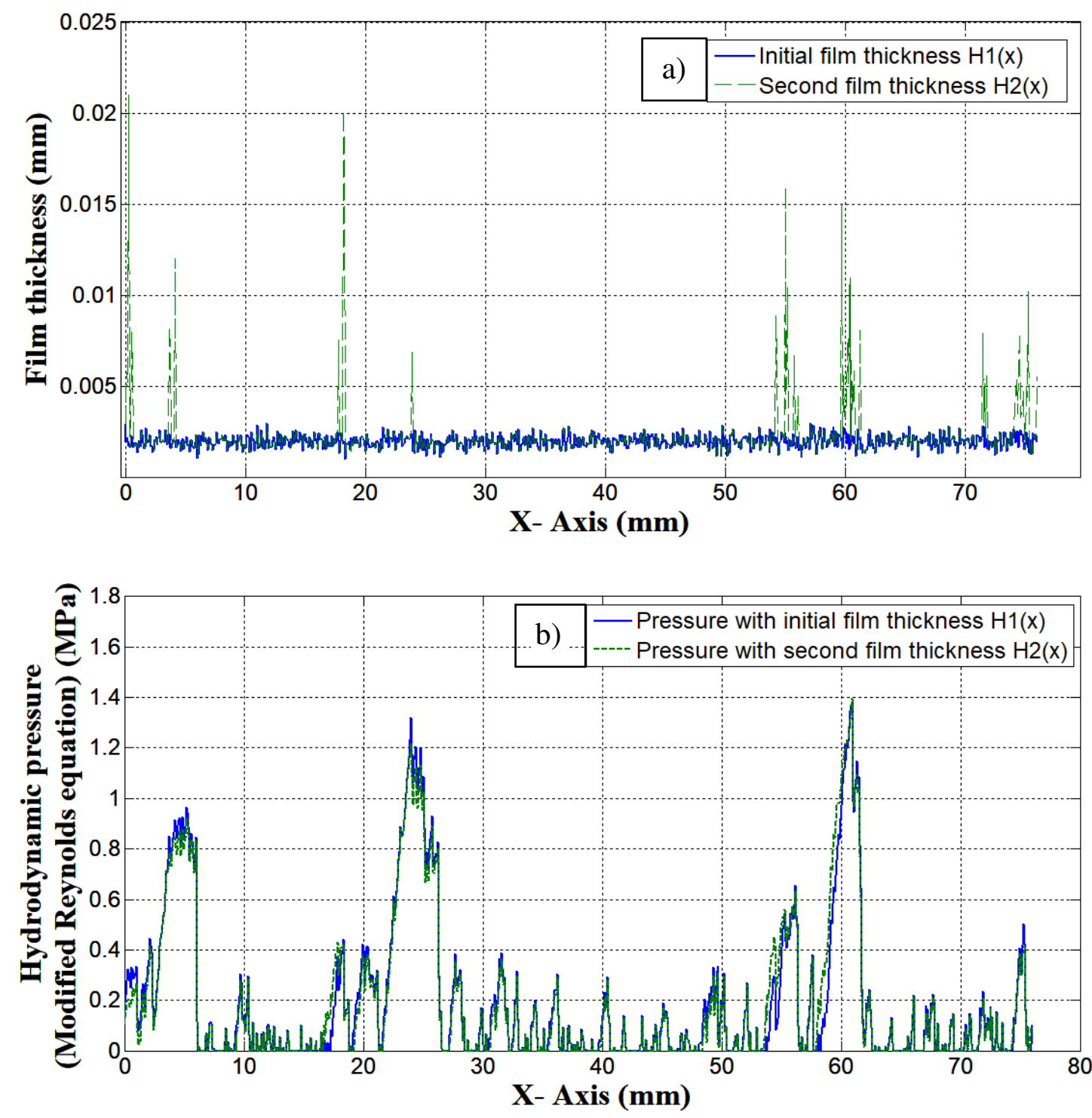

Figure 18. Comparison between hydrodynamic pressure of different film thicknesses: a) Initial film thickness $\mathrm{H}_{1}(\mathrm{x})$, b) Hydrodynamic pressure computed from $\mathrm{H}_{1}(\mathrm{x})$ and $\mathrm{H}_{2}(\mathrm{x})$ with modified Reynolds equation.

Figure 18.b confirms that the pressure has slight differences although the significant differences between surface topography, especially the Root Mean Square (RMS) $\sigma$. Thereby, it is important to note that the ratio " $h_{0} / \sigma$ " is not sufficient to determine the lubrication regime, thereby the deficiency of this ratio to define the lubrication regime as commonly known with Patir and Cheng theory. 


\section{Conclusions}

In this paper the existence of several film thicknesses that provide the same hydrodynamic pressure by considering the cavitation effect was investigated throughout three depending steps:

Step 1: With the operational conditions and an initial film thickness $\mathrm{H}_{1}(\mathrm{x})$, the hydrodynamic pressure is computed from the Reynolds equation and using the Gümbel cavitation condition.

Step 2: By using the hydrodynamic pressure of step 1 and under a specific pressure gradient condition, a second film thicknesses $\mathrm{H}_{2}(\mathrm{x})$ is found with the presented new algorithm.

Step 3: Comparing the hydrodynamic pressure accuracy of both thicknesses $\mathrm{H}_{1}(\mathrm{x})$ and $\mathrm{H}_{2}(\mathrm{x})$ computed from the mass conservation equation with the Modified Reynolds equation.

This new approach was applied for different lubricated surfaces:

- Macro-shaped surfaces: By considering initial bearing surfaces, several surfaces have been proposed that give the same hydrodynamic pressure. It was also demonstrated that with different bearing macro-shapes the frictional force varies slightly and the flow rate is regular.

- Micro-textured surfaces without cavitation: This case concerns a specific geometry condition of the surfaces that avoid the cavitation effect. By using the presented method, the initial and the second film thicknesses generate the same hydrodynamic pressure computed from the Modified Reynolds equation. 
- Micro-textured surfaces with cavitation effect: A specific geometry condition was considered to produce cavitation zones within the lubricated contact. $0.1 \%$ is a difference gap between the pressure obtained by resolving the Modified Reynolds equation with both film thicknesses.

- Rough surface: A randomized surface was considered and a second film thickness $\mathrm{H}_{2}(\mathrm{x})$ corresponding to a new roughness generating the same hydrodynamic pressure was computed. It was confirmed also that the pressure has a slight difference although the significant differences between the Root Mean Square (RMS) $\sigma$.

The effect of the separating gap between the lubricated surfaces was also investigated and the second film thickness was found. The impact of this separation is about $2 \%$ by comparing the hydrodynamic pressure for both thicknesses computed from the Modified Reynolds equation.

This paper underlines that the ratio " $\mathrm{h}_{0} / \sigma$ " is not sufficient to determine the lubrication regime as commonly known with Patir and Cheng theory. Additionally, this novel approach gives to engineers a numerical tool for changing geometry by maintaining the same lifting force and flow rate and minimizing the viscous friction effect.

It must be recalled that this method is validated without considering the dry contact phenomenon. This work opens new tracks to be investigated to be able to design lubricated contact with any pressure distribution coupled with the surface flexibility. 


\section{References}

[1] Fatu, A., Maspeyrot, P., Hajjam, M., 2011, "Wall slip effects in (elasto) hydrodynamic journal bearings," Tribology International, 44, pp. 868-877.

[2] Gherca, A.R., Maspeyrot, P., Hajjam, M., Fatu, A. , 2013, "Influence of Texture Geometry on the Hydrodynamic Performances of Parallel Bearings," Tribology Transactions, 56, pp.321-332.

[3] Kanters, A. F. C., Verest, J. F. M., Visscher, M.,1990, “On reciprocating elastomeric seals: calculation of film thicknesses using the inverse hydrodynamic lubrication theory," Tribology Transactions, 33, pp.301-306.

[4] Nikas, G. K., Sayles, R. S., 2006, "Study of leakage and friction of flexible seals for steady motion via a numerical approximation method," Tribology International, 39, pp.921-936.

[5] Fatu, A., Hajjam, M., 2011, "Numerical modelling of hydraulic seals by inverse lubrication theory", Proc. IMechE Vol. 225 Part J: J. Engineering Tribology, pp. 11591173 .

[6] Crudu, M., Fatu, A., Hajjam, M., Cristescu, C., 2013, "Numerical and experimental study of reciprocating rod seals including surface roughness effects," Sealing technology, 6, pp.8-11.

[7] Patir, N., Cheng, H. S., 1978, "An average flow model for determining effects of threedimensional roughness on partial hydrodynamic lubrication", ASLE Trans., pp. 12-17.

[8] Shen, D., Salant, R.F., 2006, "A transient mixed lubrication model of rotary lip seal with a rough shaft," STLE Tribology Transactions, 49, pp.621-634.

[9] Fowell, M., Olver, A.V., Gosman, A.D., Spikes, H.A., Pegg, I., 2007, "Entrainment and Inlet Suction: Two Mechanisms of Hydrodynamic Lubrication in TexturedBearings," ASME Journal of Tribology, 129, pp. 336-345.

[10] Fowell, M.T., Medina, S., Olver, A.V., Spikes, H.A., Pegg, I.G., 2013, "Parametric study of texturing in convergent bearings," Tribology International, 52, pp. 7-16.

[11] Gumbel, L., 1921, "Verglieich der Ergebnisse der rechnerischen Behaudlung des lagerschmierungs problem mit neuren Versuchsergebnissen", Monatsblätter d. Berlin, Bezirk V.D.I., 125-8.

[12] Lahjouji I, El Gadari M, Fahime B, Radouani M., 2017, "Effect of relative velocity between rough surfaces: hydrodynamic lubrication of rotary lip seal.” Int J Appl Mech Eng;22(2):321-332. 


\section{Nomenclature:}

F Friction force per unit length $(\mathrm{N} / \mathrm{m})$

$\mathbf{H}_{1} \quad(=\mathrm{h}(\mathrm{x}))$ Initial Film thickness $(\mathrm{mm})$

$\mathbf{H}_{2} \quad$ Second Film thickness (mm)

h Film thickness $(\mathrm{mm})$

$\mathbf{h}_{1} \quad$ Film thickness at $\mathrm{x}=0(\mathrm{~mm})$

Ku Kurtosis topography parameter

p Hydrodynamic pressure (MPa)

Q Flow rate per unit length $\left(\mathrm{mm}^{2} / \mathrm{s}\right)$

R Surface roughness ( $\mathrm{mm}$ )

r Replenishment in the cavitated zone (mm)

Ra Arithmetic roughness (mm)

Sk Skewness topography parameter

U Velocity $(\mathrm{mm} / \mathrm{s})$

W Balanced load per unit length (N/mm)

$\mathbf{x} \quad$ Axial coordinate $(\mathrm{mm})$

$\Delta \mathbf{x} \quad$ Spatial step between two successive nodes (mm)

a Entire film thickness coefficient equal to 1 or $0\left(\mathrm{~h}(\mathrm{x})\right.$ is equal to $\mathrm{H}_{1}$ or $\left.\mathrm{H}_{2}\right)$

$\boldsymbol{\sigma}$ Root Mean Square (RMS) or Standard deviation (mm)

Ф Entire cavitation coefficient (equal to 1 or 0 )

$\boldsymbol{\mu} \quad$ Lubricant viscosity (MPa.s)

\section{Tables:}

Table 1. Parameters adopted for the parametric study

Table 2. Geometry and operating conditions of the microtextured surface.

Table 3. Initial and second roughnesses corresponding to film thickness $\mathrm{H}_{1}(\mathrm{x})$ and $\mathrm{H}_{2}(\mathrm{x})$ respectively.

\section{Figures:}

Figure 1. Schematic representation of Finite Difference Approach.

Figure 2. Schematic representation of the textured pad [9]. 
Figure 3. Comparison between present model and results of [9].

Figure 4. The bearing geometry "sloping surface".

Figure 5. Hydrodynamic pressure for inclined surface bearing.

Figure 6. The film thicknesses roots: a) the initial film thickness $\mathrm{H}_{1}(\mathrm{x})$, b) the second film.

Figure 7. Examples of different bearing shapes, a) shape\#1, b) shape\#2, c) shape\#3.

Figure 8 . Hydrodynamic pressure with different bearing geometry.

Figure 9. Flow rate conservation with different bearing geometry.

Figure 10. The micro-textured bearing geometry.

Figure 11. Hydrodynamic pressure according to the initial film thickness $\mathrm{H}_{1}(\mathrm{x})$.

Figure 12. The film thicknesses roots without cavitation effect: a) the initial film thickness $\mathrm{H}_{1}(\mathrm{x})$, b) the second film thickness computed from equations (13) and (14).

Figure 13. Hydrodynamic pressure with the different micro-textured surfaces without cavitation.

Figure 14. Hydrodynamic pressure with the initial film thickness $\mathrm{H}_{1}(\mathrm{x})$.

Figure 15. The film thicknesses roots with cavitation effect: a) the initial film thickness $\left.\mathrm{H}_{1}(\mathrm{x}), \mathrm{b}\right)$ the second film thickness computed from equations (13) and (14).

Figure 16. Comparison between the hydrodynamic pressure provided by initial film thickness $\mathrm{H}_{1}(\mathrm{x})$ and the second film thickness $\mathrm{H}_{2}(\mathrm{x})$.

Figure 17. Comparison between three separating gaps: a) initial film thickness $\mathrm{H}_{1}(\mathrm{x})$, b) Hydrodynamic pressure corresponding to $\mathrm{H}_{1}(\mathrm{x})$ with Gümbel model, c) Second film 
thickness $\mathrm{H}_{2}(\mathrm{x})$, d) Difference between hydrodynamic pressure computed from $\mathrm{H}_{1}(\mathrm{x})$ and $\mathrm{H}_{2}$ (x) with modified Reynolds equation.

Figure 18. Comparison between hydrodynamic pressure of different film thicknesses:

a) Initial film thickness $\mathrm{H}_{1}(\mathrm{x})$, b) Hydrodynamic pressure computed from $\mathrm{H}_{1}(\mathrm{x})$ and $\mathrm{H}_{2}(\mathrm{x})$ with modified Reynolds equation. 
Figures

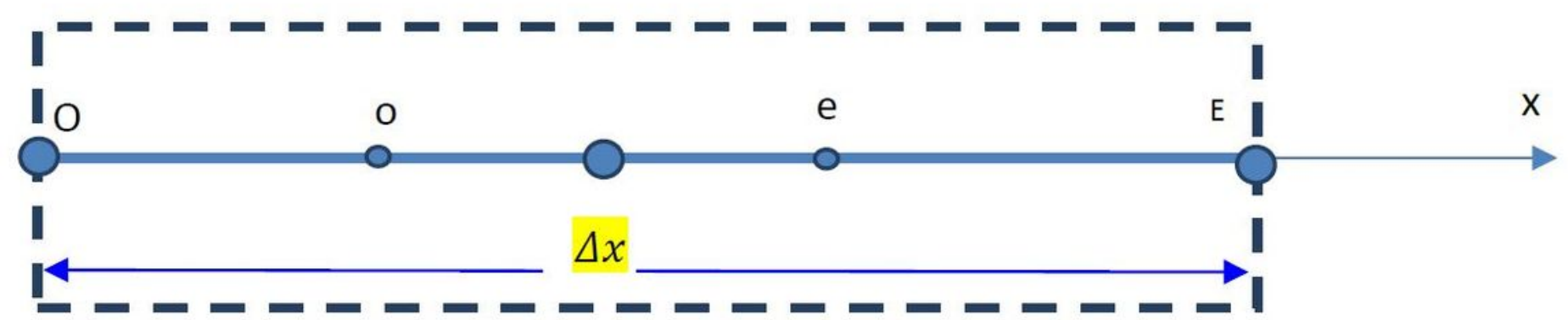

Figure 1

Schematic representation of Finite Difference Approach

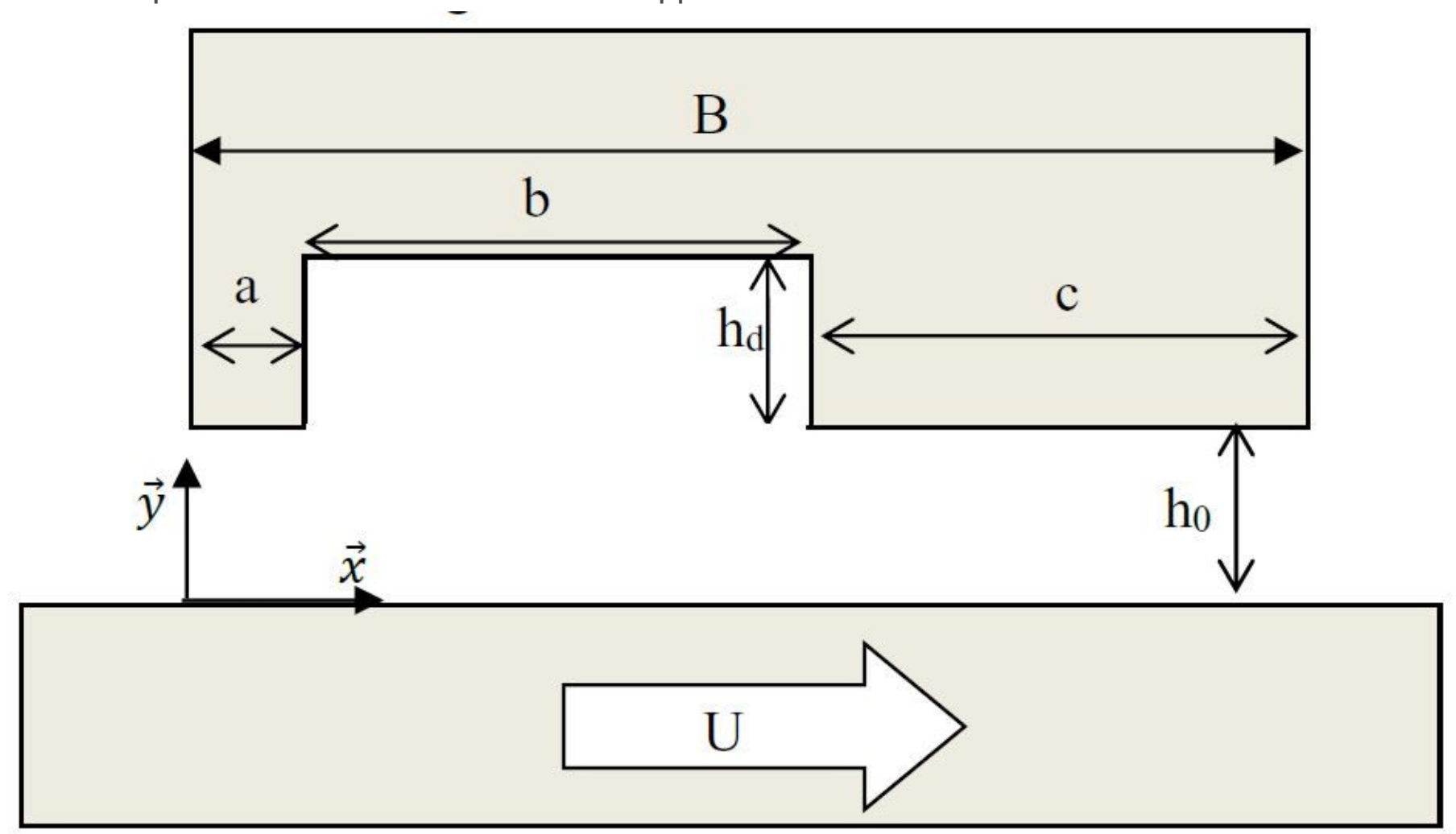

Figure 2

Schematic representation of the textured pad [9] 


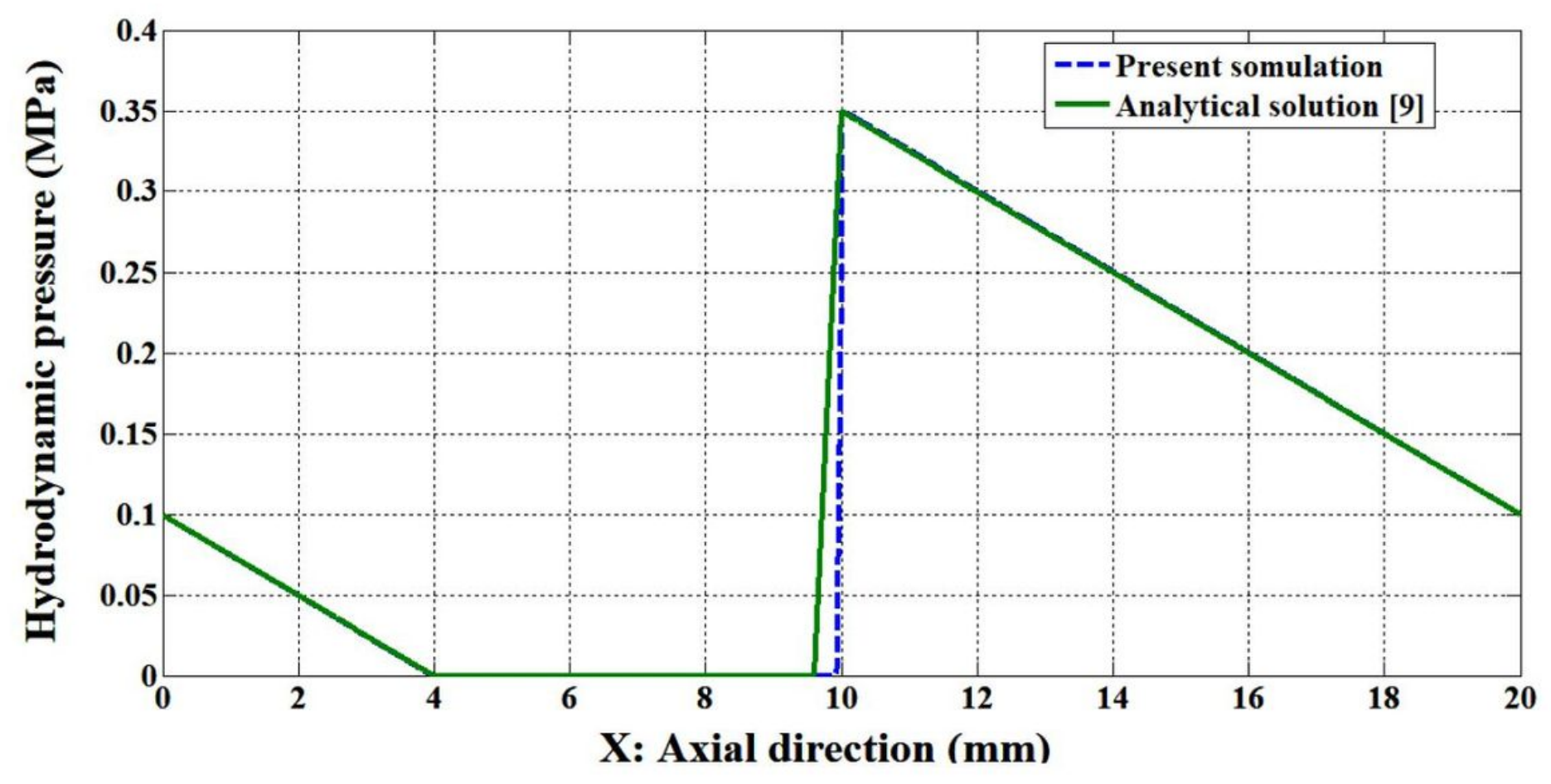

Figure 3

Comparison between present model and results of [9]

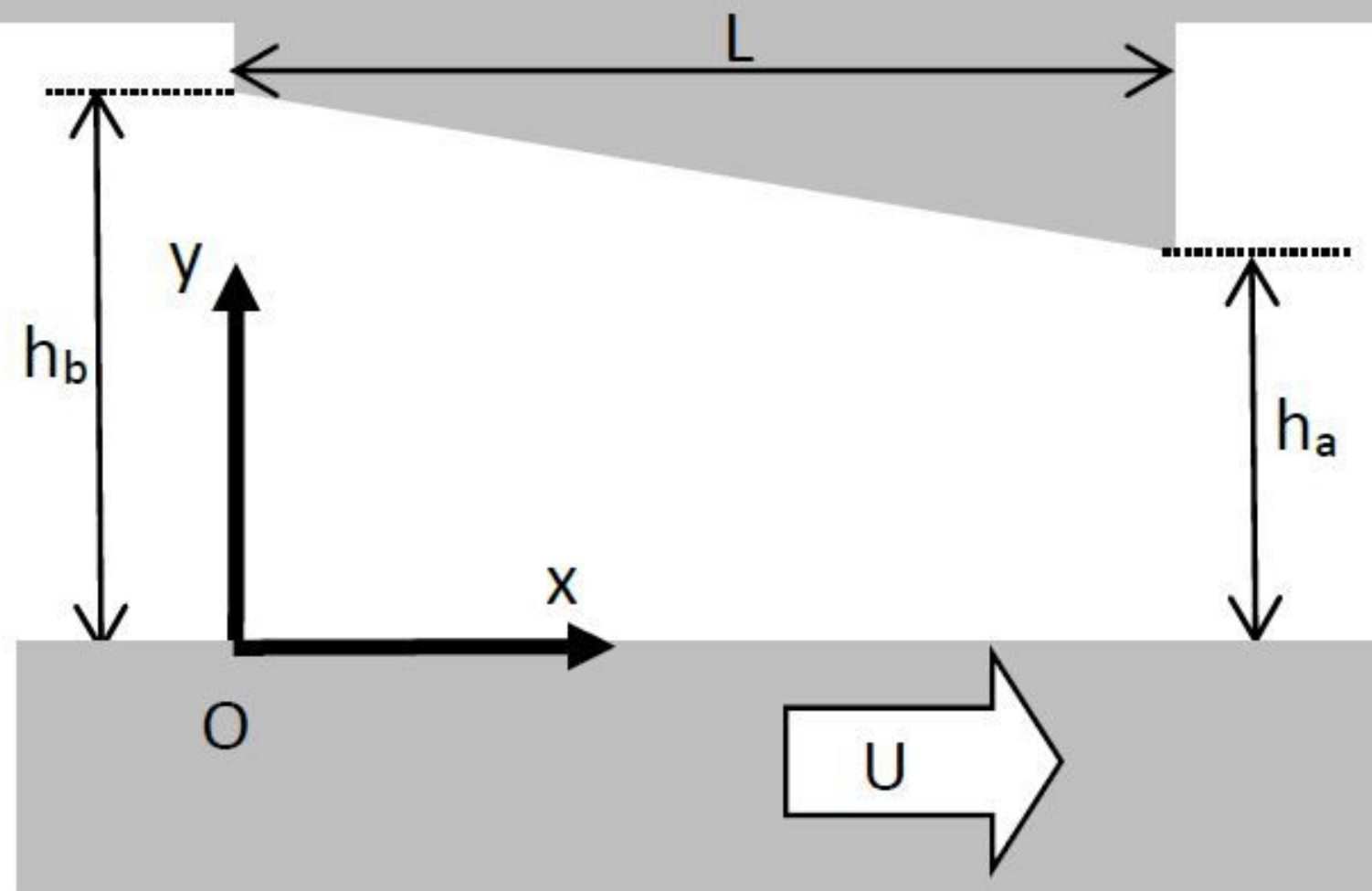

Figure 4 
The bearing geometry "sloping surface"

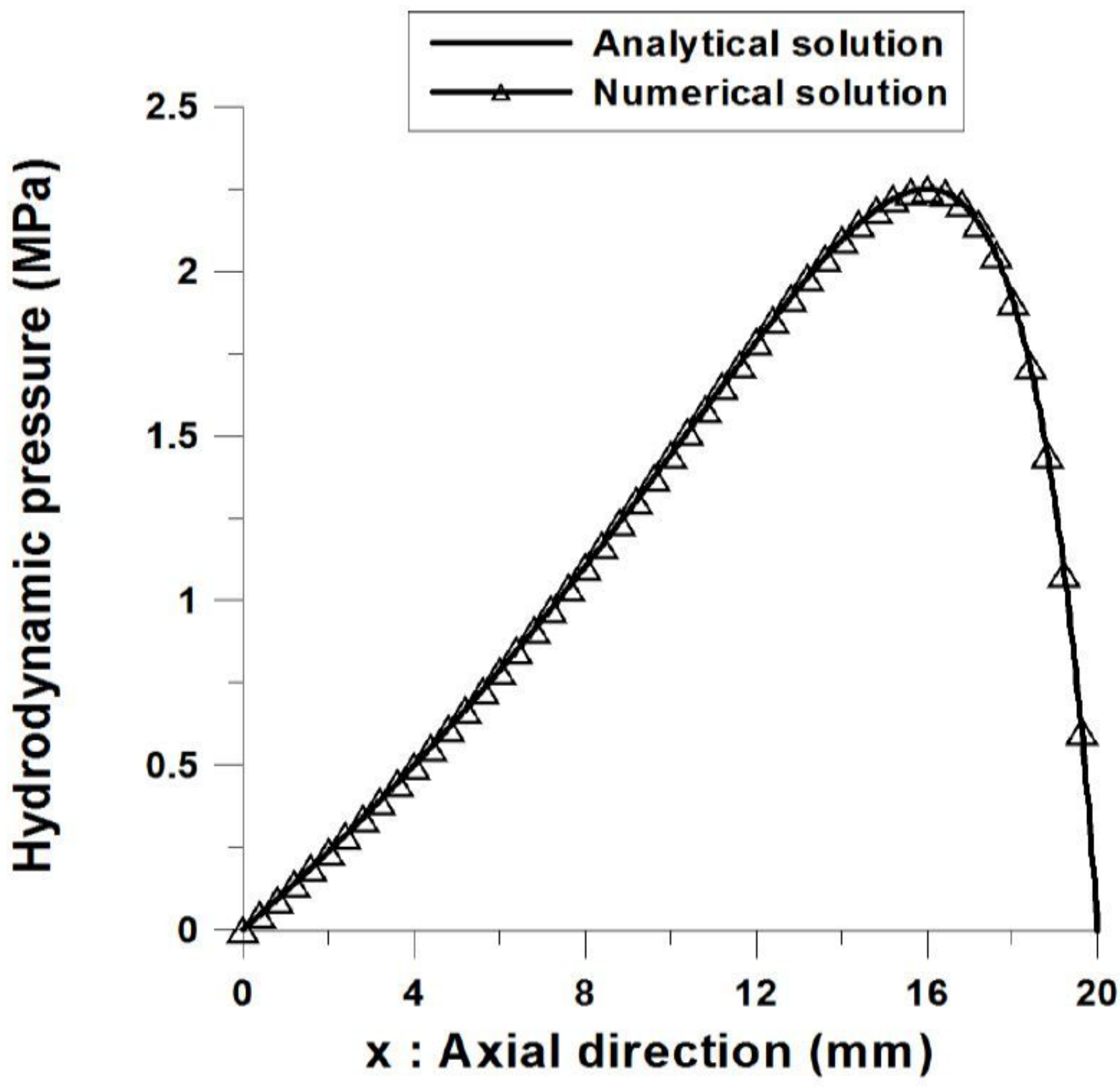

Figure 5

Hydrodynamic pressure for inclined surface bearing 

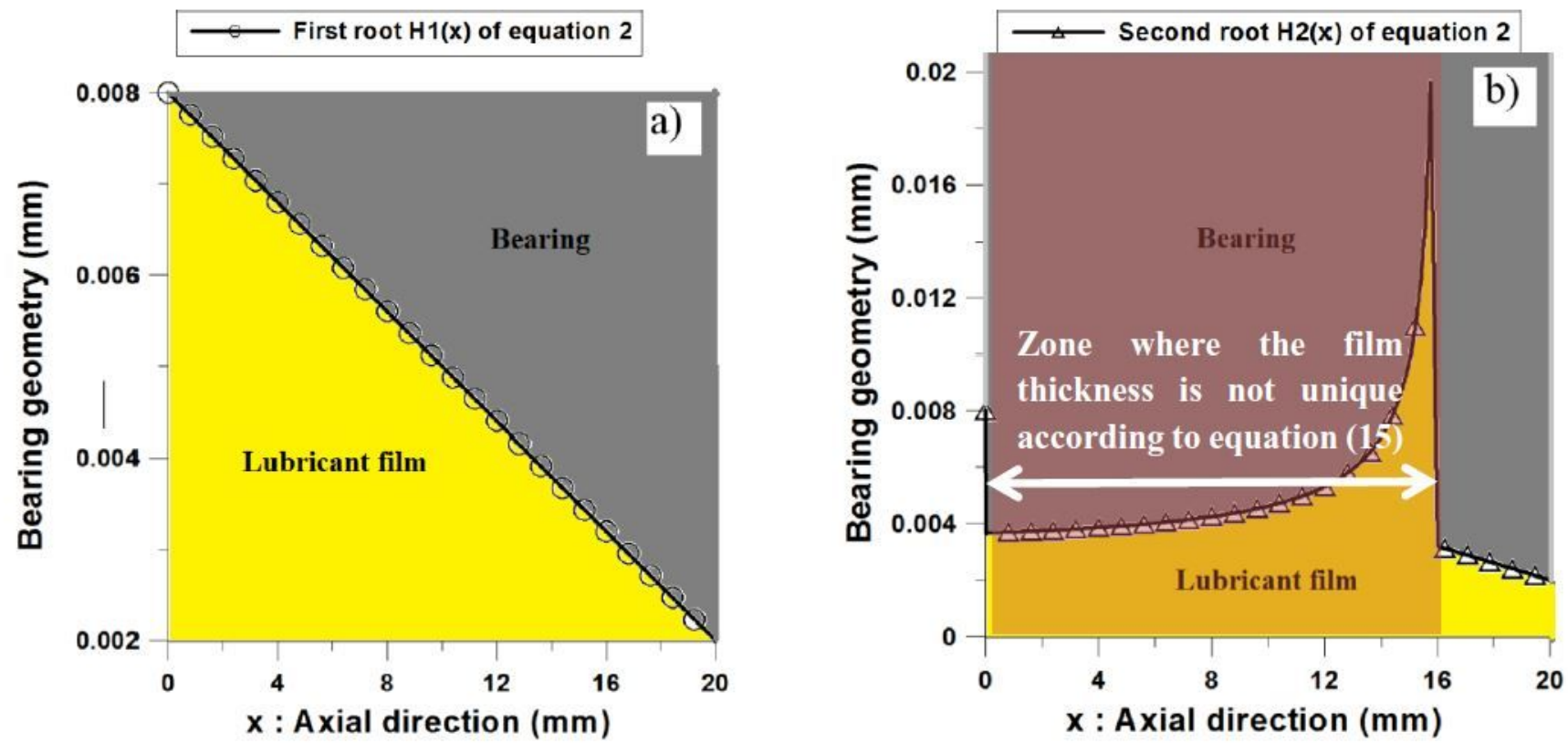

Figure 6

The film thickness roots: a) the initial film thickness $\mathrm{H} 1(\mathrm{x}), \mathrm{b})$ the second film thickness computed from equation (13) and (14)
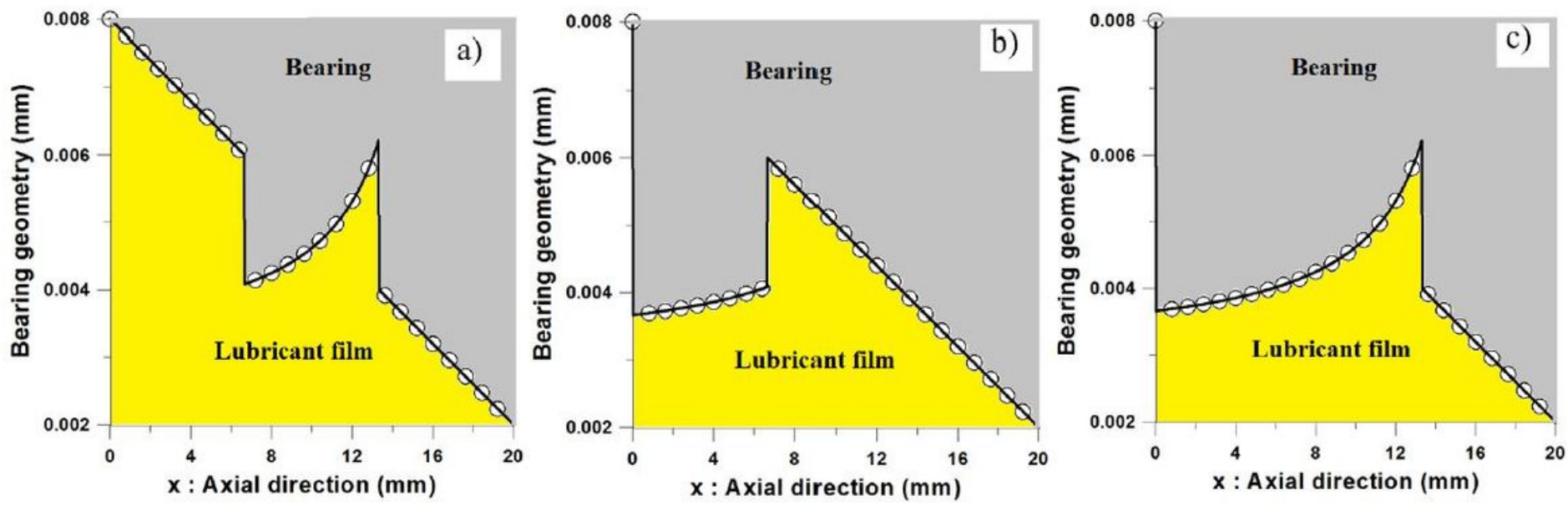

Figure 7

Examples of different bearing shape, a) shape\#1, b) shape\#2, c) shape\#3 


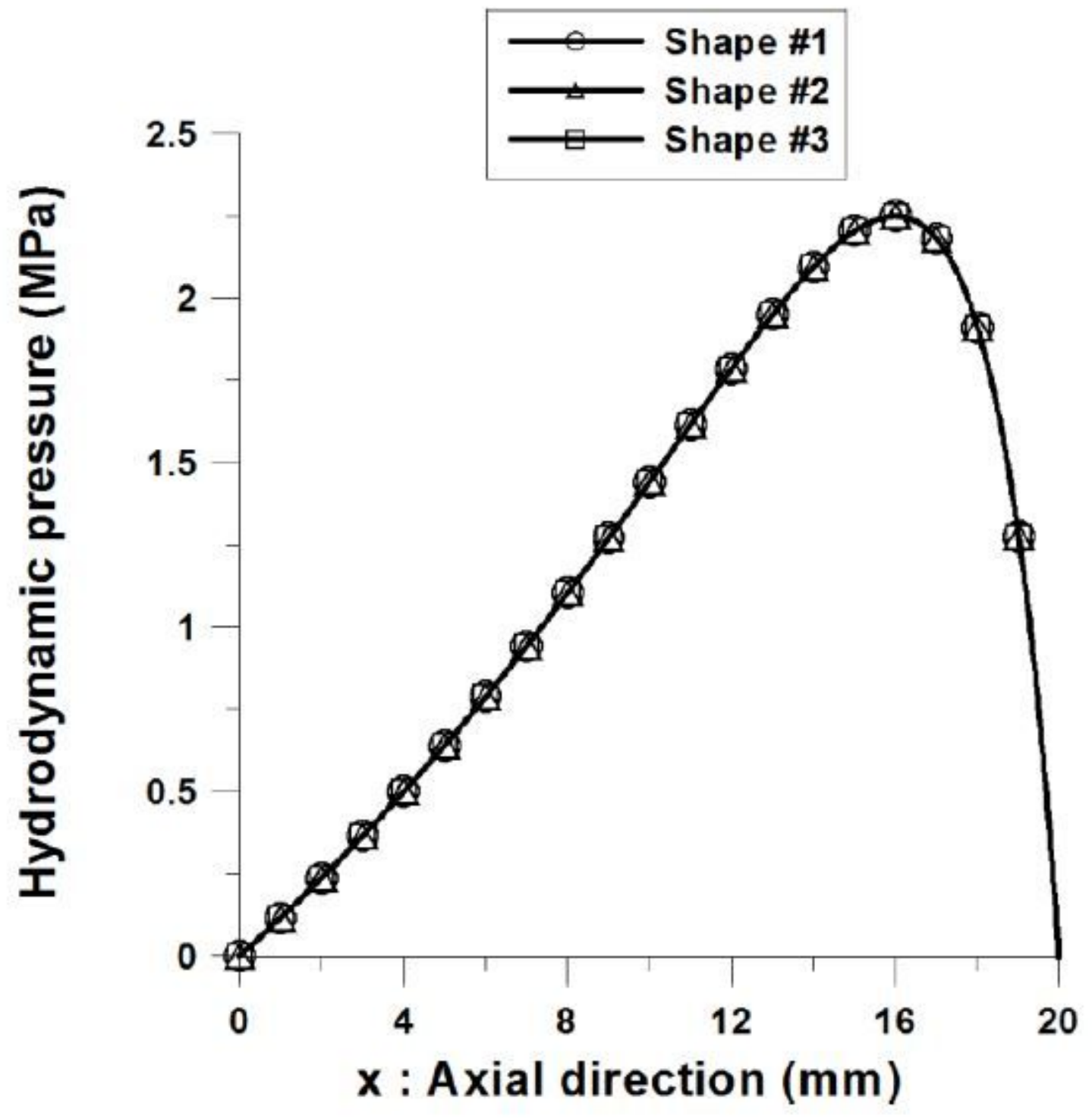

Figure 8

Hydrodynamic pressure with different bearing geometry 


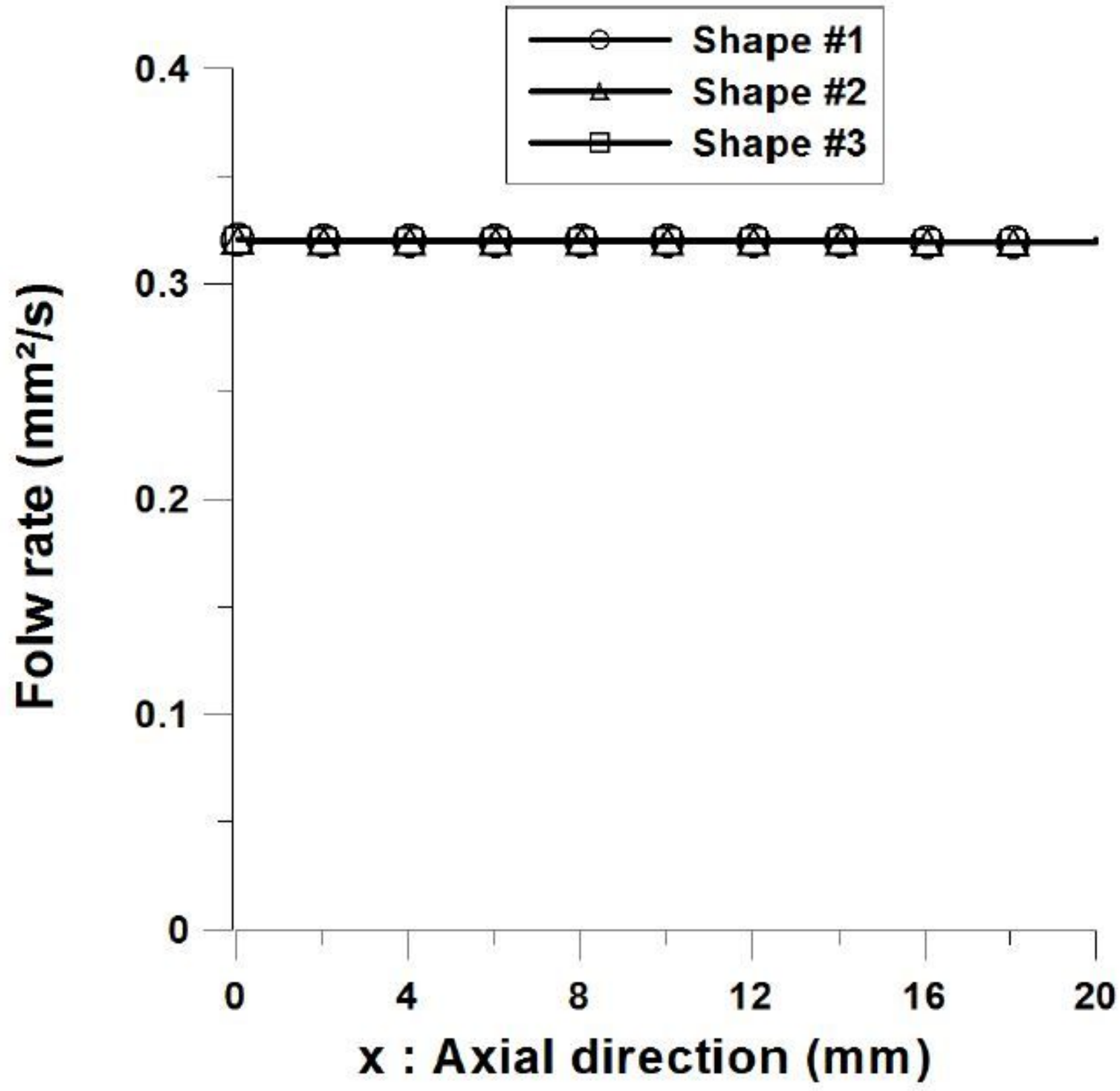

Figure 9

Flow rate conservation with different bearing geometry

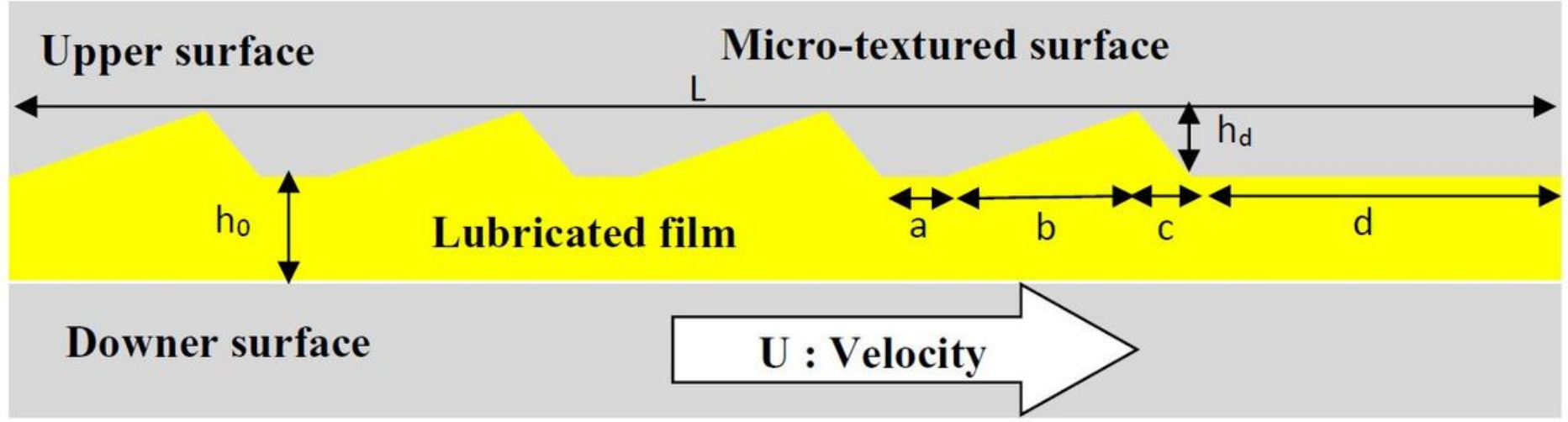


Figure 10

The micro-textured bearing geometry.

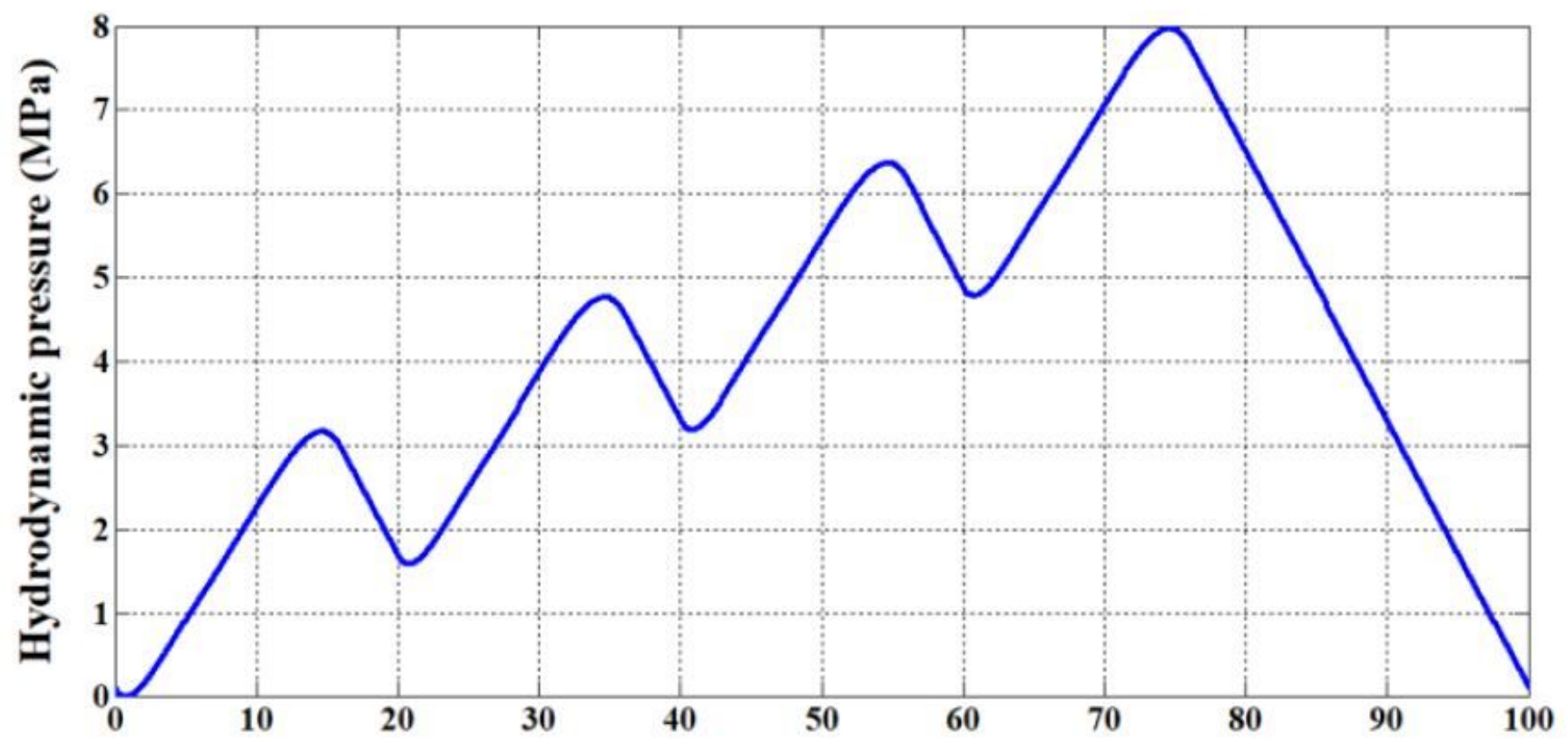

\section{Figure 11}

Hydrodynamic pressure according to the initial film thickness $\mathrm{H} 1(\mathrm{x})$
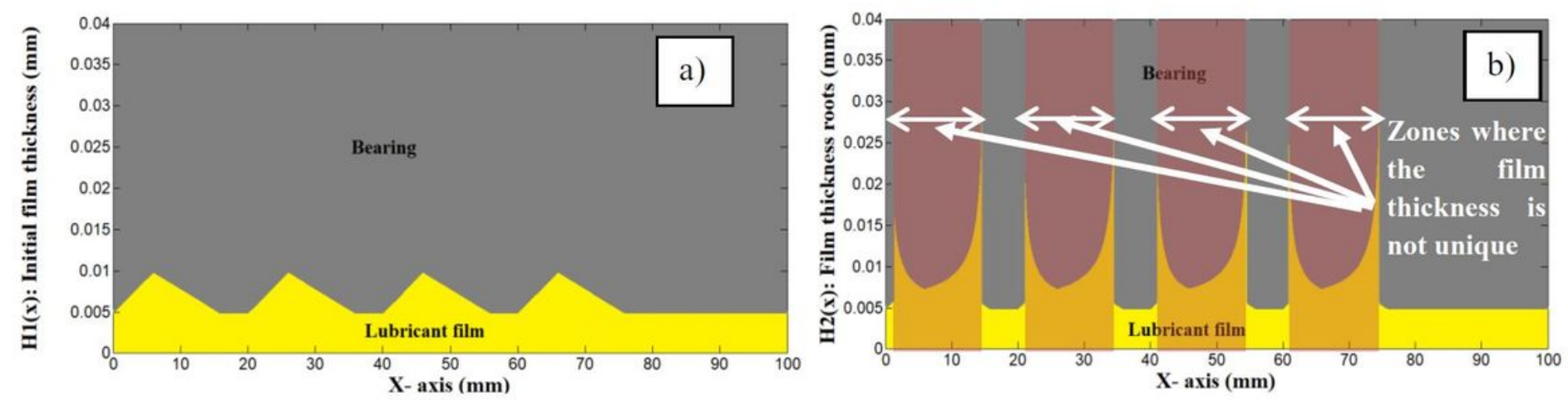

Figure 12

The film thicknesses roots without cavitation effect: a) the initial film thickness $\mathrm{H} 1(\mathrm{x}), \mathrm{b})$ the second film thickness computed from equations (13) and (14) 


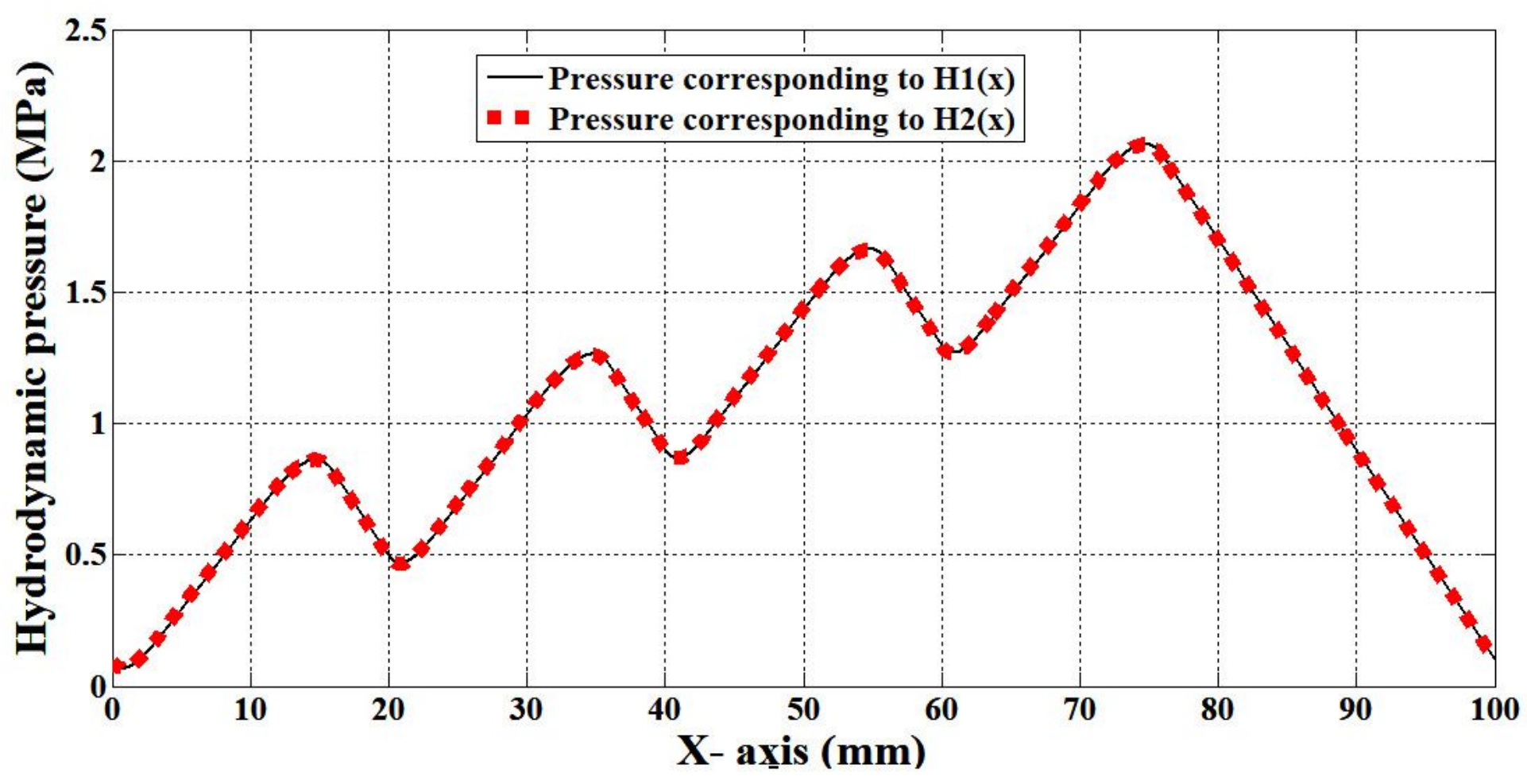

Figure 13

Hydrodynamic pressure with the different micro-textured surface without cavitation

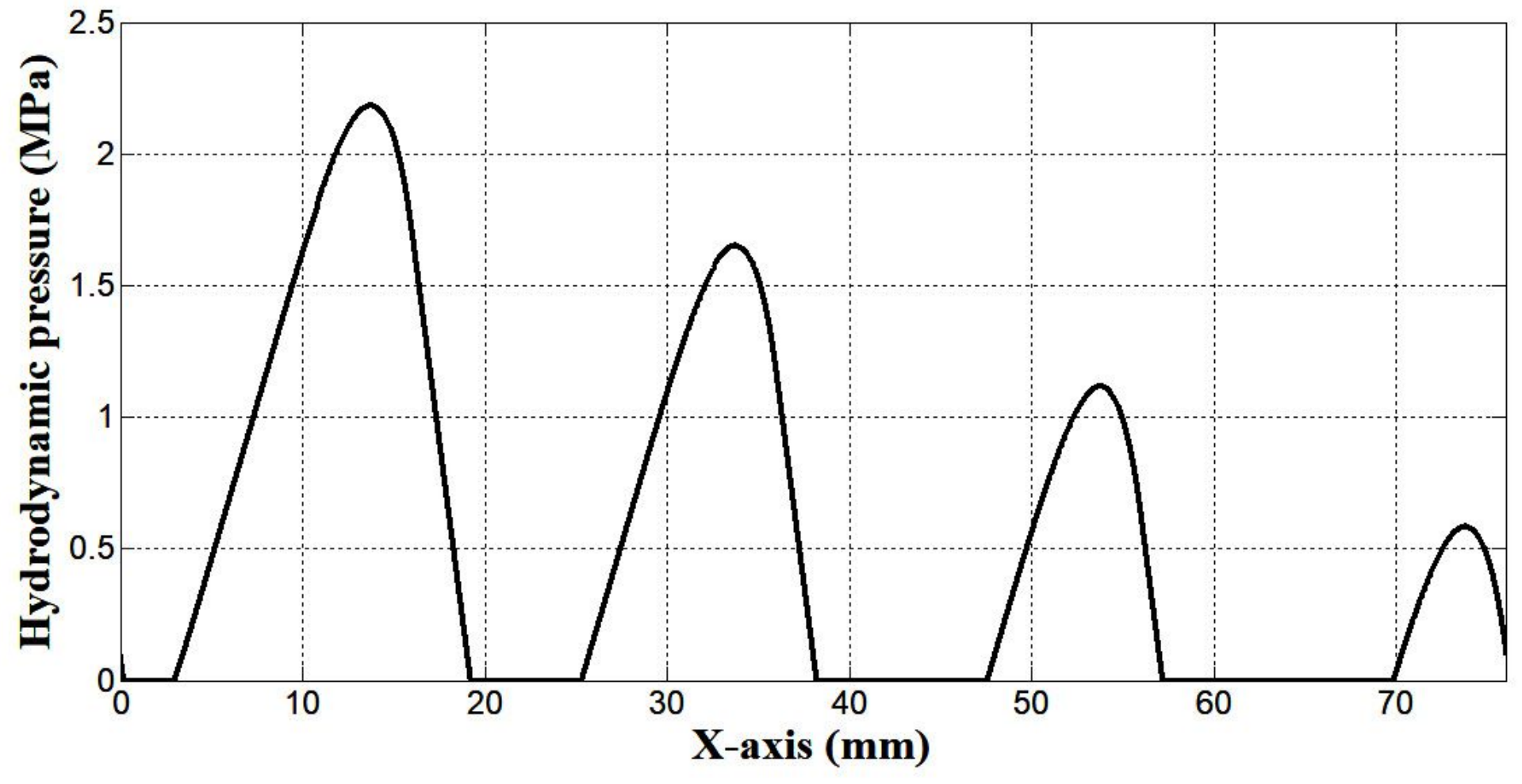

Figure 14

Hydrodynamic pressure with the initial film thickness $\mathrm{H} 1(\mathrm{x})$ 

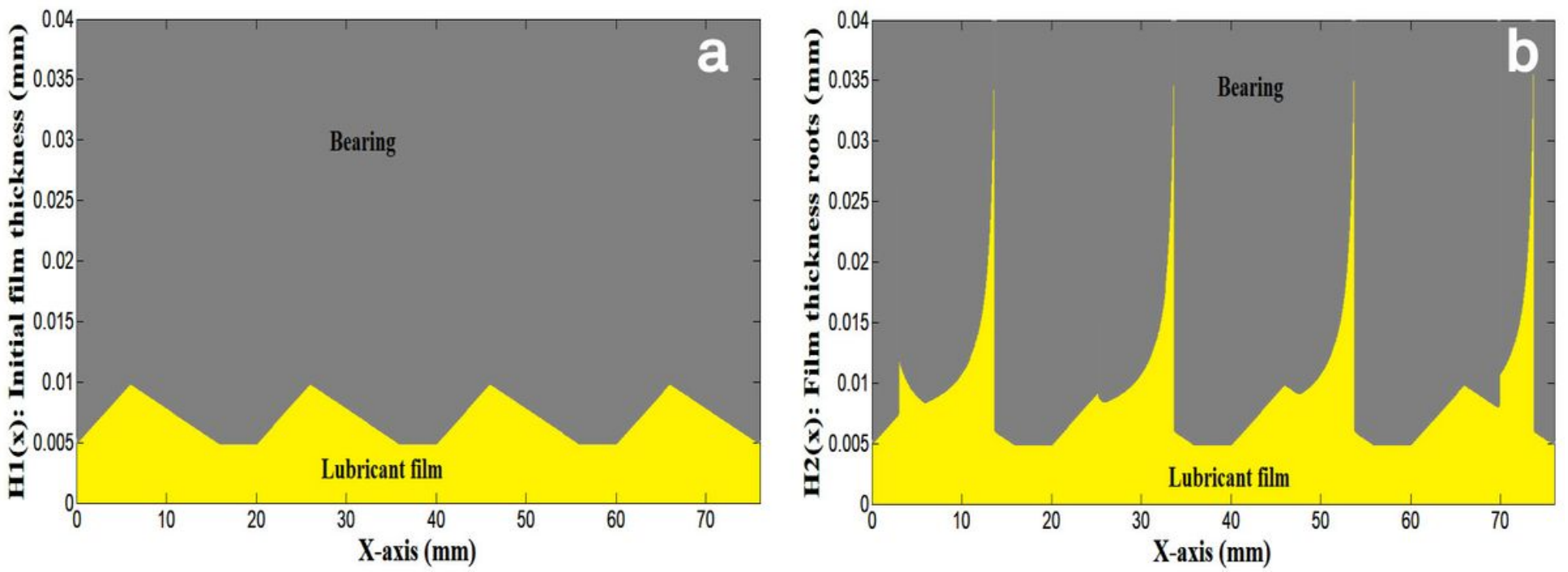

Figure 15

The film thicknesses roots with cavitation effect: a) the initial film thickness $\mathrm{H} 1(\mathrm{x}), \mathrm{b})$ the second film thickness computed from equations (13) and (14)

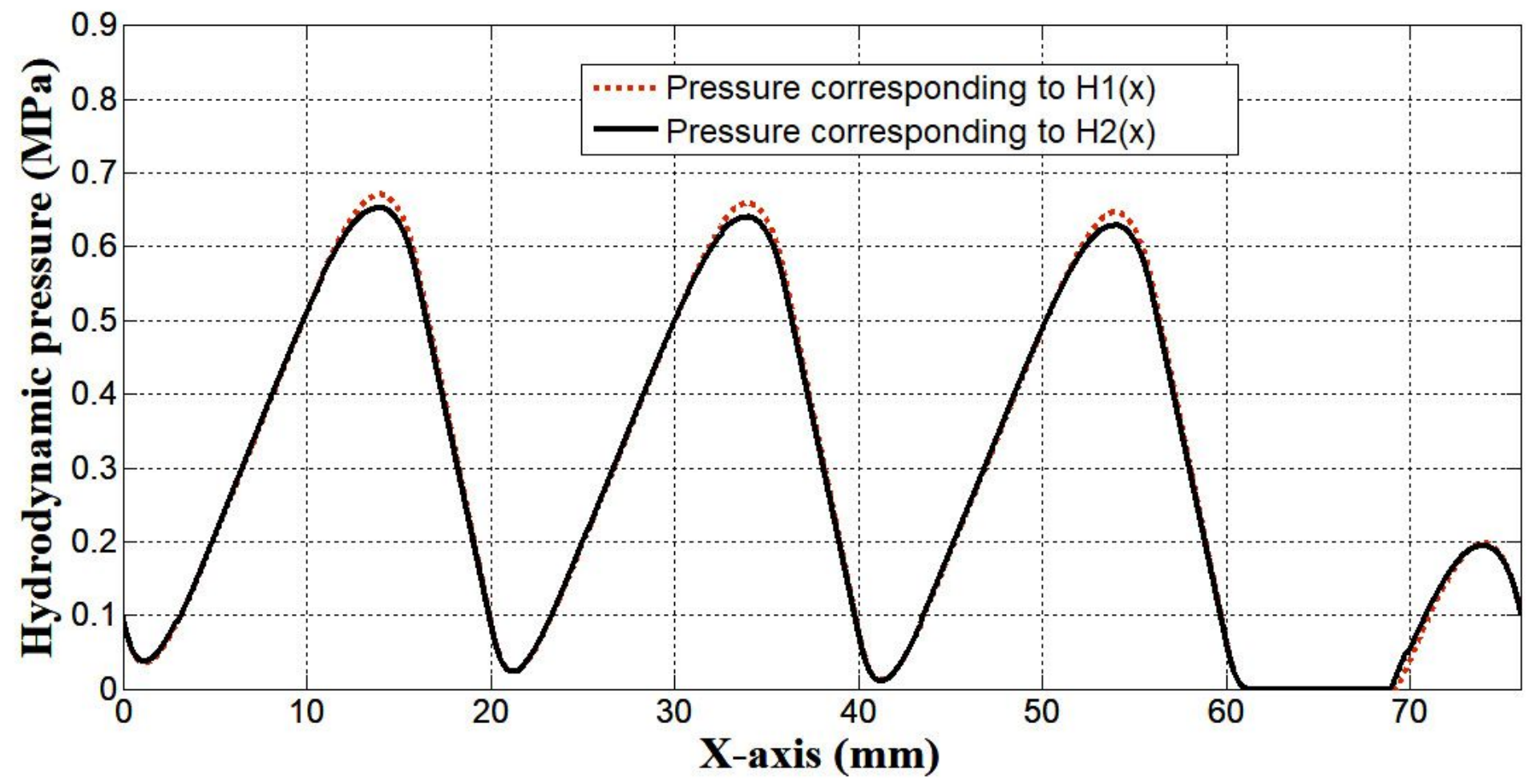

Figure 16

Comparison between the hydrodynamic pressure provided by initial film thickness $\mathrm{H} 1(\mathrm{x})$ and the second film thickness $\mathrm{H} 2(\mathrm{x})$. 

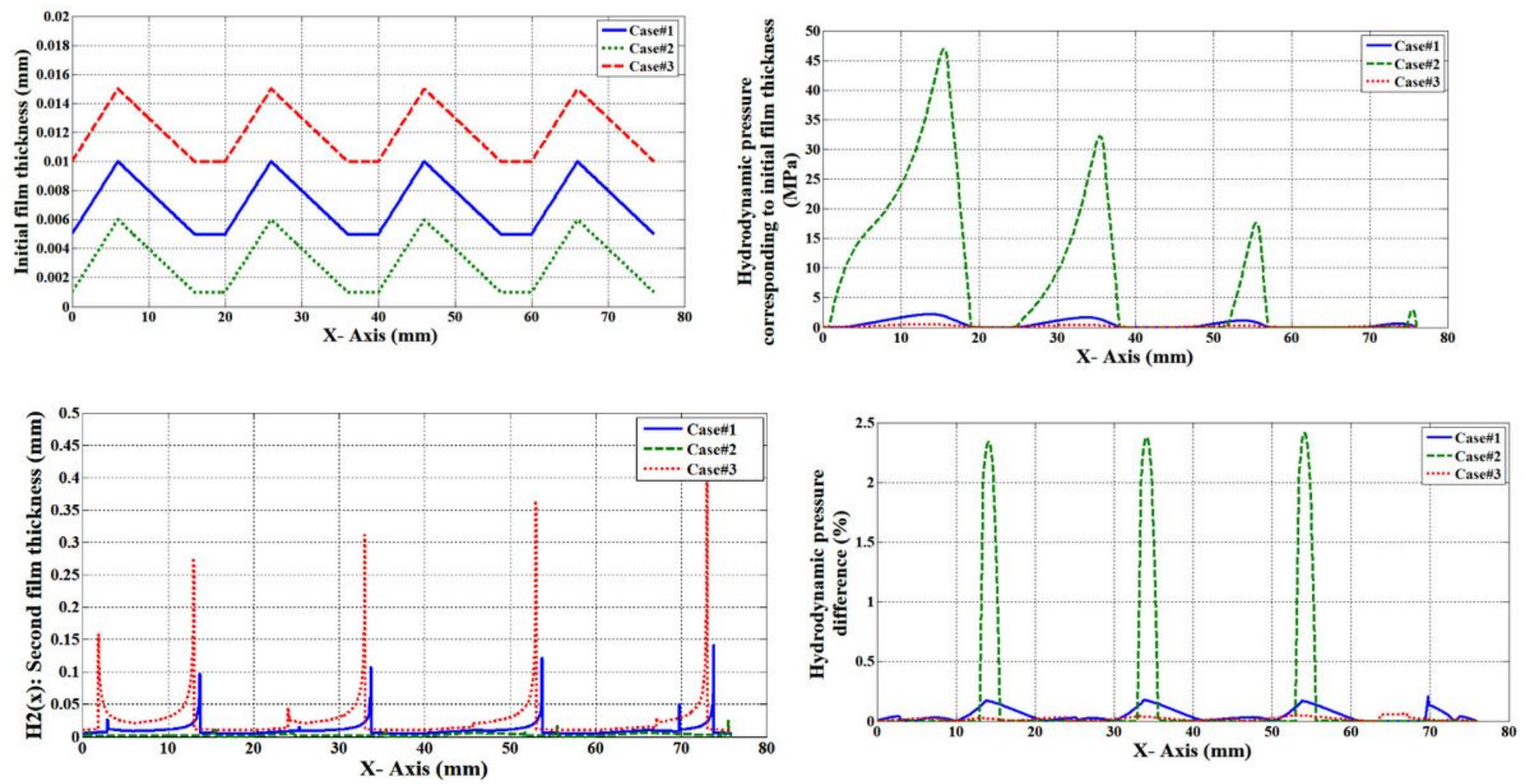

Figure 17

Comparison between three separating gaps: a) initial film thickness $\mathrm{H} 1(\mathrm{x}), \mathrm{b})$ Hydrodynamic pressure corresponding to $\mathrm{H} 1(\mathrm{x})$ with Gümbel model, c) Second film thickness $\mathrm{H} 2(\mathrm{x})$, d) Difference between hydrodynamic pressure computed from $\mathrm{H} 1(x)$ and $\mathrm{H} 2(x)$ with modified Reynolds equation. 

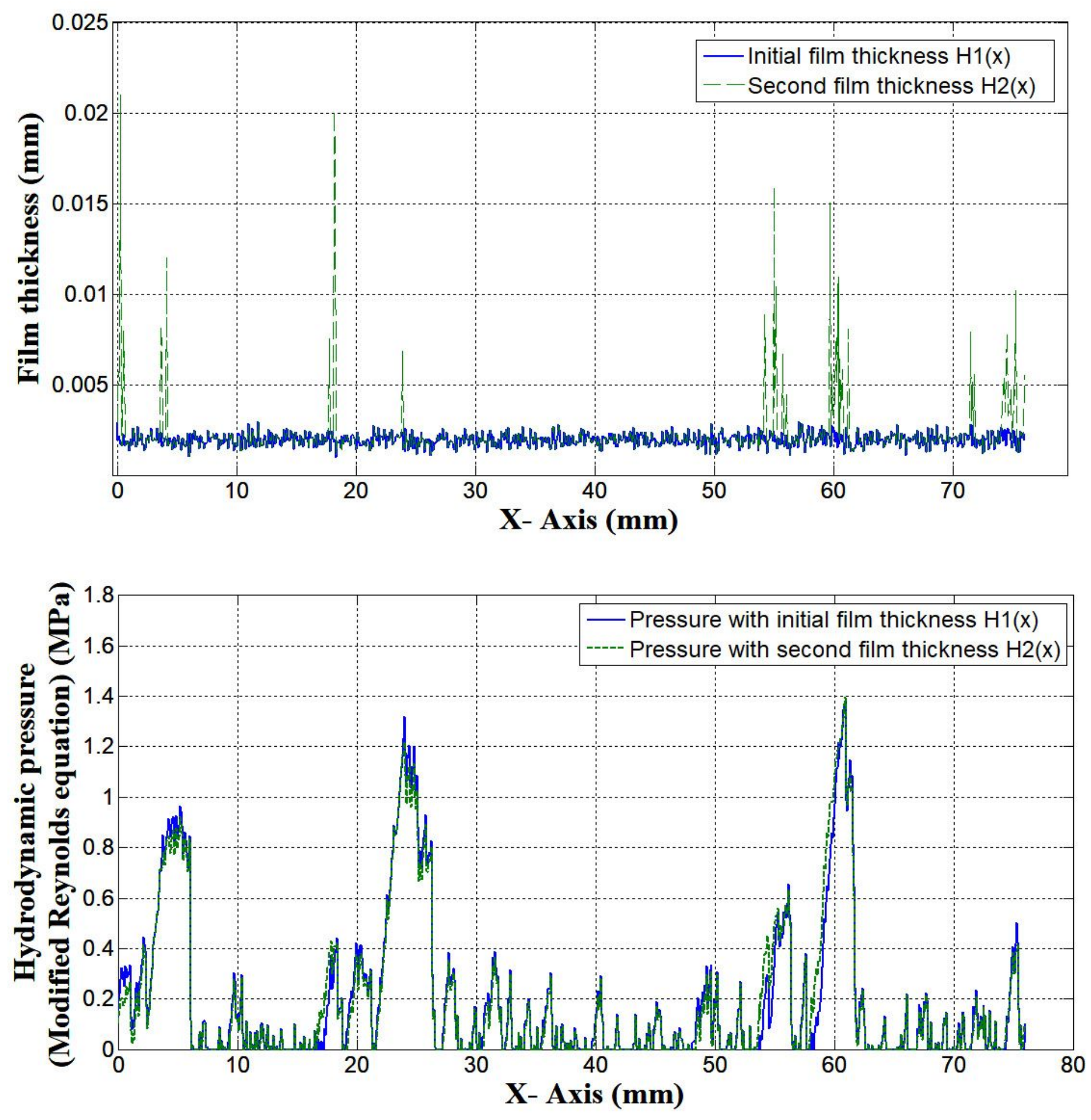

Figure 18

Comparison between hydrodynamic pressure of different film thicknesses: a) Initial film thickness $\mathrm{H} 1(\mathrm{x})$, b) Hydrodynamic pressure computed from $\mathrm{H} 1(\mathrm{x})$ and $\mathrm{H} 2(\mathrm{x})$ with modified Reynolds equation. 